\title{
Towards a Unified Understanding of Lithium Action in Basic Biology and its Significance for Applied Biology
}

\author{
Eric Jakobsson ${ }^{1,2,5,6,7,8}$ (I) $^{3}$ Orlando Argüello-Miranda ${ }^{9}$ See-Wing Chiu ${ }^{1,7}$. \\ Zeeshan Fazal $^{3,4} \cdot$ James Kruczek $^{10} \cdot$ Santiago Nunez-Corrales ${ }^{7,11}$. \\ Sagar Pandit ${ }^{10} \cdot$ Laura Pritchet ${ }^{6,12}$
}

Received: 22 July 2017/Accepted: 21 October 2017/Published online: 10 November 2017

(c) The Author(s) 2017. This article is an open access publication

\begin{abstract}
Lithium has literally been everywhere forever, since it is one of the three elements created in the Big Bang. Lithium concentration in rocks, soil, and fresh water is highly variable from place to place, and has varied widely in specific regions over evolutionary and geologic time. The biological effects of lithium are many and varied. Based on experiments in which animals are deprived of lithium, lithium is an essential nutrient. At the other extreme, at lithium ingestion sufficient to raise blood concentration significantly over $1 \mathrm{mM} /$, lithium is acutely toxic. There is no consensus regarding optimum levels of lithium intake for populations or individuals-with the single exception that lithium is a generally accepted firstline therapy for bipolar disorder, and specific dosage
\end{abstract}

Electronic supplementary material The online version of this article (https://doi.org/10.1007/s00232-017-9998-2) contains supplementary material, which is available to authorized users.

Eric Jakobsson

jake@illinois.edu

1 Beckman Institute for Advanced Science and Technology, University of Illinois at Urbana-Champaign, Urbana, IL, USA

2 Center for Biophysics and Computational Biology, University of Illinois at Urbana-Champaign, Urbana, IL, USA

3 Department of Biosciences, COMSATS Institute of Information Technology, Islamabad, Pakistan

4 Department of Animal Sciences, University of Illinois at Urbana-Champaign, Urbana, IL, USA

5 Carl R. Woese Institute for Genomic Biology, University of Illinois at Urbana-Champaign, Urbana, IL, USA

6 Neuroscience Program, University of Illinois at UrbanaChampaign, Urbana, IL, USA guidelines for sufferers of that condition are generally agreed on. Epidemiological evidence correlating various markers of social dysfunction and disease vs. lithium level in drinking water suggest benefits of moderately elevated lithium compared to average levels of lithium intake. In contrast to other biologically significant ions, lithium is unusual in not having its concentration in fluids of multicellular animals closely regulated. For hydrogen ions, sodium ions, potassium ions, calcium ions, chloride ions, and magnesium ions, blood and extracellular fluid concentrations are closely and necessarily regulated by systems of highly selective channels, and primary and secondary active transporters. Lithium, while having strong biological activity, is tolerated over body fluid concentrations ranging over many orders of magnitude. The lack of biological regulation of lithium appears due to lack of lithium-specific binding sites and selectivity filters. Rather lithium exerts its myriad physiological and biochemical

7 National Center for Supercomputing Applications, University of Illinois at Urbana-Champaign, Urbana, IL, USA

8 Department of Molecular and Integrative Physiology, University of Illinois at Urbana-Champaign, Urbana, IL, USA

9 Department of Cell Biology, UT Southwestern Medical Center, Dallas, TX, USA

10 Department of Physics, University of South Florida, Tampa, FL, USA

11 Illinois Informatics Institute, University of Illinois at UrbanaChampaign, Urbana, IL, USA

12 Present Address: Department of Psychological and Brain Sciences, University of California at Santa Barbara, Santa Barbara, CA, USA 
effects by competing for macromolecular sites that are relatively specific for other cations, most especially for sodium and magnesium. This review will consider what is known about the nature of this competition and suggest using and extending this knowledge towards the goal of a unified understanding of lithium in biology and the application of that understanding in medicine and nutrition.

Keywords Ion channels and transporters - Magnesiumdependent enzymes - Physical properties of biological membranes

\section{Organization of this Paper}

We will initially describe the origins of lithium and cite the evidence that lithium is readily transported across membranes but not closely regulated in body fluids. We will further note the absence of evidence for specific lithium transporters or channels, or as a specific cofactor for biological molecules. Evidence for transport and for other biological effects, combined with lack of evidence for specificity, implies that lithium exerts its effects by competing with regulated cations for permeation and binding sites. We will then review and discuss literature describing lithium competitive association and its biological significance in the following contexts:

- Origins of lithium in the environment

- Physical similarities and differences between lithium and other biologically important cations

- Significance and mechanisms for lithium passage across biological membranes

- Lithium interaction with membranes

- Lithium competition with magnesium

- Lithium and mitochondria

- Lithium as a nutrient and a toxin

- Lithium and affective disorders

- Lithium, GSK3, and BDNF-Connecting the dots between lithium, stress, affective disorders, and neurodegenerative disease

- Lithium and cancer

- Lithium in the model eukaryote Yeast

- Origins and evolution of lithium in biology

Because of the broad scope of this review, the citation list will be representative rather than exhaustive.

A note on terminology: All biological activity that we know of, and is described in this paper and the cited papers, is with the ion $\mathrm{Li}+$. It has become common practice in the biological literature to use the word "lithium" when describing the biological activity of $\mathrm{Li}+$, with the ionic form understood in the context of the biology. In this review, we adopt this practice except when citing particular papers that use the $\mathrm{Li}+$ notation.

\section{Origins of Lithium in the Environment}

Lithium was one of the three elements produced in the initial condensation of matter from energy immediately following the Big Bang (Fields and Olive 2006). It is widely and unevenly distributed across the surface of the earth in both igneous and sedimentary rock (Turekian and Wedepohl 1961). Its concentration in water is governed by a balance between weathering from rocks into waterways and deposition from water into sediments. Seawater is well mixed with respect to lithium; the concentration is relatively uniform at an average of approximately $.025 \mathrm{mM}$ (Schwochau 1984). Lithium levels in freshwater are lower than in seawater and highly variable from location to location. For example, in well water in the United States, lithium concentrations vary from less than $.00014 \mathrm{mM}$ to greater than $.007 \mathrm{mM}$ (Ayotte et al. 2011). This variability is due to the variations from place to place and throughout evolutionary and geologic time of weathering processes that began shortly after the formation of the earth (Ushikubo et al. 2008). It is from water that lithium moves into living systems, by mechanisms that will be reviewed in this paper.

\section{Physical Similarities and Differences Between Lithium and Other Biologically Important Cations}

$\mathrm{Li}+$ is a monovalent cation. Among the monovalent cations, lithium is the smallest, and sodium the next smallest. Naively, one would expect lithium to compete better for access to sodium sites and transport mechanisms than those of other univalent cations, and this is indeed true, as will be seen in the literature reviewed in this paper. Comparing lithium to divalent cations, the ionic radius of lithium is almost the same as magnesium. Naively, one might expect lithium to compete better with magnesium than with other divalent cations, and this is indeed true as will be reviewed in this paper. In fact, it appears that most of the major biological effects of lithium can plausibly be explained as competition with sodium and magnesium, the ions most like lithium by measures of charge and size. In detail, the underlying physics is associated with the energetic cost for each ion of exchanging its bulk aqueous environment for the complex hybrid aqueous-organic molecule environment of an ion associated with a macromolecule (Varma and Rempe 2008). While the general principles of such selectivity are understood, applying those principles to any case is far from trivial, involving detailed knowledge of the structures of ion-selective biomolecules. A notable paper reported engineering the transformation of a sodium-calcium antiporter into a 
sodium/lithium-calcium antiporter (Refaeli et al. 2016). This work may help towards a detailed physical understanding of sodium/lithium competition and selectivity. It should also be noted that lithium has been shown to associate with magnesium-ATP (Briggs et al. 2016). The biological importance of ATP leads one to consider to what extent lithium-ATP association may contribute to the overall biological effects of lithium, but at present the connection is not clear.

\section{Significance and Mechanisms for Lithium Passage Across Biological Membranes}

de Roos et al. showed that over a wide range of lithium oral ingestion, lithium levels in blood plasma are almost directly proportional to lithium ingestion (de Roos et al. 2001). This property enables nutrition researchers to use a lithium marker to monitor compliance with controlled diets (Donahoo et al. 2004). From these gross observations it can be inferred that lithium is transported, but that its concentration is not regulated. The lack of regulation is in sharp contrast to other biologically important cationssodium, potassium, calcium, protons, and magnesiumwhose blood concentration is closely regulated. The mechanisms of such regulation are largely (although not totally) understood, and are described in standard textbooks. These mechanisms involve ion permeation and transport mechanisms that are highly specific for the ions being regulated. To date, no transport mechanisms specific for lithium have been identified. On the other hand, there are abundant reports of lithium competition for access to transport mechanisms and binding sites that are otherwise largely specific to closely regulated ions.

One major pathway for lithium entry into cells is through sodium channels, of the voltage-gated class (Richelson 1977), and also of the non-voltage-gated epithelial class (Thomsen and Shirley 2006). A detailed structure and function study of a prokaryotic sodium channel that has strong homology to eukaryotic voltagegated sodium channels, revealed approximately equal permeability of lithium and sodium (Naylor et al. 2016). Lithium reabsorption in the kidney appears to be largely by its ability to utilize the sodium-phosphate cotransporter in the nephron proximal tubule (Uwai et al. 2014). Without this mechanism, lithium concentrations in the body would be much lower than they in fact are. Lithium substitution for sodium in the environment of a sodium-aspartate cotransporter drives aspartate transport, albeit much less effectively than sodium (Boudker et al. 2007). Both lithium and sodium enter potassium channels, but apparently block rather than permeate (Thompson et al. 2009). Lithium also has some ability to enter calcium channels and inhibit calcium permeation (Kuo and Hess 1993). However, for both potassium and calcium channels, significant inhibition of the channel ionic flux by lithium is achieved only at concentrations far exceeding what can be achieved in living systems. In this case, the value of this knowledge is biophysical, using lithium as a probe for the details of permeation mechanism, rather than understanding the role of lithium in the living system.

In some cases, lithium substitutes for sodium weakly or not at all. One example is sodium-activated potassium channels, for which lithium is a significantly less effective activator than sodium (Kaczmarek 2013). Also, lithium does not effectively replace sodium in sodium-glucose cotransport in the gut epithelium (Csaky 1961).

Lithium efflux from cells is also sodium dependent, as evidenced by observations that lower concentrations of extracellular sodium cause a reduction in lithium efflux in red blood cells (Canessa et al. 1980) and neurons (Szentistvanyi et al. 1979). Experiments on lymphoid cells in which both intracellular and extracellular concentrations are varied suggest that one component of the sodium-dependent lithium efflux is from a sodium-lithium countertransport system in which both sodium and lithium can go both ways (Yurinskaya et al. 2014). The existence of such a system is further supported by a computational model incorporating such a system to explain the data (Vereninov et al. 2016). However, to date, no gene has been identified corresponding to this countertransport. A major mechanism for lithium efflux, for which the gene has been identified, is the sodium-proton pump (Busch et al. 1995). In this case, intracellular lithium competes with protons for access to the pump for ejection from the cell. The efflux of lithium occurs as an example of a general class of secondary active transport mechanisms that are driven by sodium gradients (Krishnamurthy et al. 2009).

Furthermore, lithium also permeates pentameric ligandgated cation channels (Lewis and Stevens 1983; Grosman, Claudio 2016. Personal communication based on unpublished observations).

In addition to epithelial and nonepithelial cell membranes, lithium transport across mitochondrial membranes is significant. Lithium provides protection against damage to brain mitochondria exposed to elevated calcium (Shalbuyeva et al. 2007). It is plausible that this lithium-dependent protection is mediated by the mitochondrial $\mathrm{Na}+/$ $\mathrm{Ca}++$ exchanger (NCLX), whose primary function is to mediate sodium-calcium exchange across the mitochondrial outer membrane, and is also an efficient lithium-calcium exchanger (Boyman et al. 2013). There are many other ion transport mechanisms across the mitochondria outer and inner membranes that are potential pathways for lithium transport (Szabo and Zoratti 2014) but their role in transporting lithium has not been reported. 
Because the biomolecules that move lithium across membranes in multicellular animals have homologues in prokaryotes (BLAST search, unpublished), it appears that living systems have taken up lithium from their surroundings from very early in evolution.

Intracellular lithium concentrations are seldom measured, but one study found that the ratio of intracellular to extracellular lithium concentrations in red blood cells is approximately one-half (Mendels and Frazer 1973). Major mechanisms by which lithium crosses membranes, and which, therefore, account for the transmembrane distribution, are summarized graphically in Fig. 1.

\section{Lithium Interaction with Membranes}

Published information about the interaction of lithium with membranes is fragmentary but suggests that such interactions are biologically significant. A deuterium NMR study explored the ability of potassium, sodium, lithium, magnesium, and calcium ions to alter the structure of 1-palmitoyl-2-oleoyl-3-glycero-phosphatidylserine (POPS) and (1-palmitoyl-2-oleoyl-3-glycero-phosphatidylcholine (POPC) membranes (Roux and Bloom 1990). This study found that lithium penetrated the membranes more deeply, and altered membrane structure to a greater degree, than sodium or potassium but not quite as much as the divalent cations. The effect of ions on modulating the diffusivity of hydration water near the surface of a POPC vesicle was explored using Overhauser dynamic nuclear polarization (Song et al. 2014). It was found that sodium and potassium increased the activation energy for water motion, while lithium and calcium reduced such energy. In another study, microelectrophoresis was used to determine the degree of association of different alkali metal ions with phosphatidylcholine (PC) membranes (Kotyńska et al. 2016). It was found lithium had the highest overall affinity for the membranes. Studies based on zeta potential find that lithium has the highest affinity of all alkali metal ions for a mixed PC-PG membrane (Maity et al. 2016). The ordering of ionic affinities as a function of counterions and of headgroups can be ordered into a Hofmeister-like series (Vlachy et al. 2009). A computational study of alkali metal ions and POPC membranes confirmed the high affinity of lithium and showed that lithium-induced conformational changes in the head groups that were not seen with the other ions (Kruczek et al. 2017). The nature of the conformational change is illustrated in Fig. 2. This figure shows a snapshot of a typical situation in the abovecited molecular dynamic simulations in which a lithium ion has penetrated the interior of a POPC bilayer and induced a tetrahedral cage structure involving four negatively charged groups from three different phospholipid molecules. This geometry is like the tetrahedral structure formed by water molecules around the lithium ion in solution. The larger alkali metal ions can't readily form these tetrahedral structures in the membrane and have larger coordination numbers than four for their inner hydration shell in solution (Mähler and Persson 2011).

Lithium was reported to compete with both calcium and magnesium for specific sites in phosphatidylcholine-phosphatidylglycerol membranes (Fossel et al. 1985).

In biological membranes of mixed composition, it was found that lithium treatment of experimental animals altered the fluidity of neural plasma membrane (LopezCorcuera et al. 1988). The changed fluidity appeared to be not due to direct interaction of the lithium with the membrane but rather to metabolic effects of lithium that, over course of the lithium treatment, altered the saturation of the lipid chains in the membrane. A more recent study utilizing C6 glioma cells indicates that the distribution of the signal protein GS alpha is moved into lipid rafts by lithium (Donati et al. 2015). It is not clear whether this reorganization of the membrane was due to direct effect of lithium or due to lithium-induced metabolic changes that modified the membrane composition.

\section{Lithium Competition with Magnesium}

It has long been known that in rocks and clays of all ages and across the world, lithium and magnesium readily substitute for each other (Goldschmidt 1937). This is attributed to the fact that their ionic radii are almost identical to each other, and quite different from the ionic radii of other plentiful monovalent and divalent ions. With a similar size, we might expect lithium and magnesium to compete for the same binding sites in biomolecules, despite the different magnitude of their charge. In early work, Birch noted the systematic tendency of lithium to inhibit magnesium-dependent enzymes (Birch 1974). We now have many more published examples of such competition. Lithium appears to inhibit $\beta$-adrenergic and muscarinic receptor coupling to $G$ proteins by competing with magnesium, which facilitates such coupling (Avissar et al. 1991; de Mota de Freitas et al. 2006; Yoshikawa and Honma 2016; Bauer and Gitlin 2016; Wang and Friedman 1999). A particularly important example is substitution of a lithium ion for a magnesium ion acting as a cofactor in inositol monophosphatase, a putative critical molecular target for lithium therapy for bipolar disease (Singh et al. 2013). In this protein, the binding site for lithium is not revealed in crystallography nor in solution NMR but can be identified in magic angle spinning solid state NMR, which is more suitable for systems with large internal motion (Haimovich et al. 2012). Another target of lithium, also a 
(a)

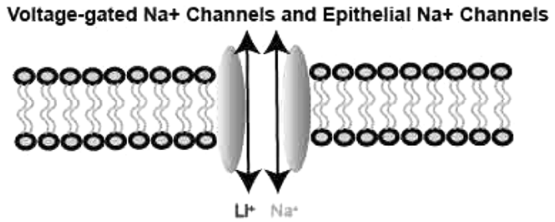

(c)

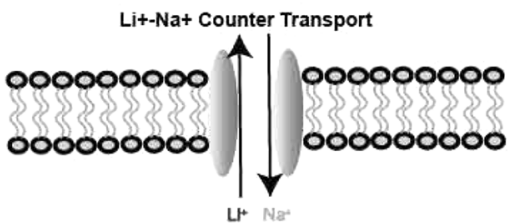

(e)

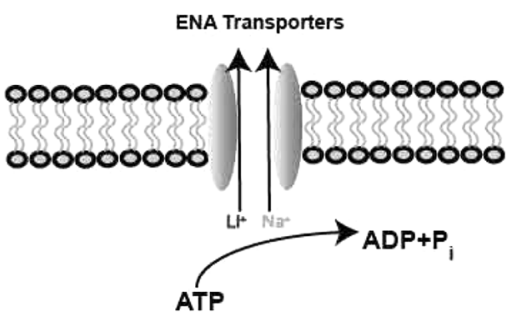

(g)

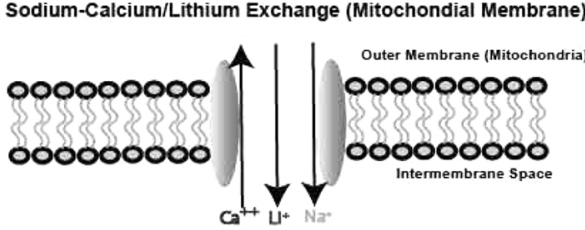

(b) Kidney Sodium-Phosphate Co-Transporter

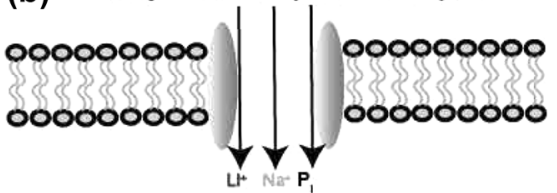

(d)

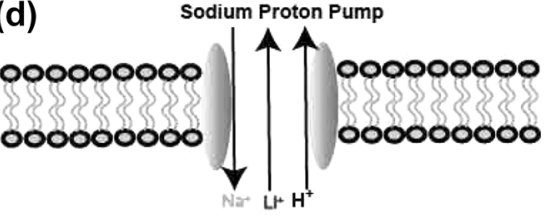

(f)
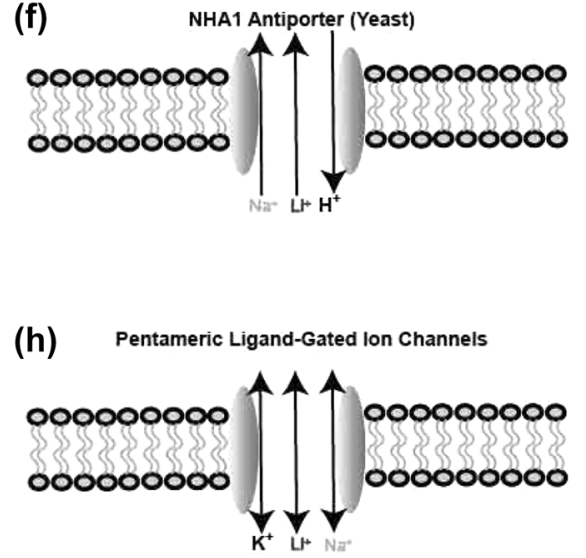

Fig. 1 Major mechanisms by which lithium crosses biological membranes. a Lithium permeates both voltage-gated (Richelson 1977; Naylor et al. 2016) and epithelial (Thomsen and Shirley 2006) channels that are otherwise selective for sodium. b Lithium is reabsorbed in the kidney by the sodium-phosphate cotransporter (Uwai et al. 2014). c A major mechanism for lithium efflux from cells is a sodium-lithium countertransport (Szentistvanyi et al. 1979; Yurinskaya et al. 2014; Vereninov et al. 2016). d Another significant lithium efflux mechanism is the sodium-proton pump (Busch et al. 1995). e Members in yeast of the ENA family of cation-transport ATPases move lithium as well as sodium (Ruiz and Arino 2007).

magnesium-dependent phosphatase and with relevance to neural effects, is bisphosphate 3-prime-nucleotidase (BPNT1) (Spiegelberg et al. 2005; Meisel and Kim 2016). These findings are consistent with a hypothesis that lithium inhibits magnesium-dependent enzymes by displacing magnesium from its binding site thereby reducing the structural stability and lowering activity of the enzyme.

One mode of action with many consequences is lithium inhibition of glycogen synthase kinase 3beta (GSK3B), initially shown in vitro and in intact cells (Stambolic et al. 1996), and in the context of embryonic development (Klein and Melton 1996). It was later shown that lithium exerted its inhibitory effect on GSK3B by competing with magnesium for an essential binding site (Ryves and Harwood 2001). There are two closely related forms of GSK3, termed alpha (GSK3A) and beta (GSK3B), which are equivalently inhibited by lithium (Freland and Beaulieu
Based on sequence homology, we hypothesize that the mammalian members of the family will share this functional feature. $\mathbf{f}$ The NHA1 antiporter in yeast is important for both sodium and lithium efflux (Prior et al. 1996). This antiporter does not appear to have mammalian orthologs. g Lithium protects mitochondria against the effects of elevated calcium (Shalbuyeva et al. 2007), presumably through its action in the sodium-calcium antiporter in the mitochondrial outer membrane (Boyman et al. 2013). h Lithium permeates pentameric ligand-gated ion channels (Grosman, Claudio 2016. Personal communication based on unpublished observations; Lewis and Stevens 1983)

2012). The two forms of GSK3 have substantial functional redundancy (Doble et al. 2007). However, some of their physiological properties are different, as demonstrated by the fact that GSK3B knockout mice are not viable (Hoeflich et al. 2000), but GSK3A knockout mice survive (MacAulay et al. 2007). The very widespread nature of GSK3B effects is related to the large number of transcription factors that it regulates (Grimes and Jope 2001). It functionally modulates cellular threshold for apoptosis (Beurel and Jope 2006), it is central to mediating mitochondrial response to stress; (Juhaszova et al. 2004) it facilitates immune responses by enabling the nuclear export of NF-ATc; (Beals et al. 1997) it regulates inflammation; (Beurel et al. 2010) it regulates cardiac hypertrophy and development (Hardt and Sadoshima 2002), to name just a few. Based on microarray studies of brain cells in animals, lithium alters gene expression patterns 


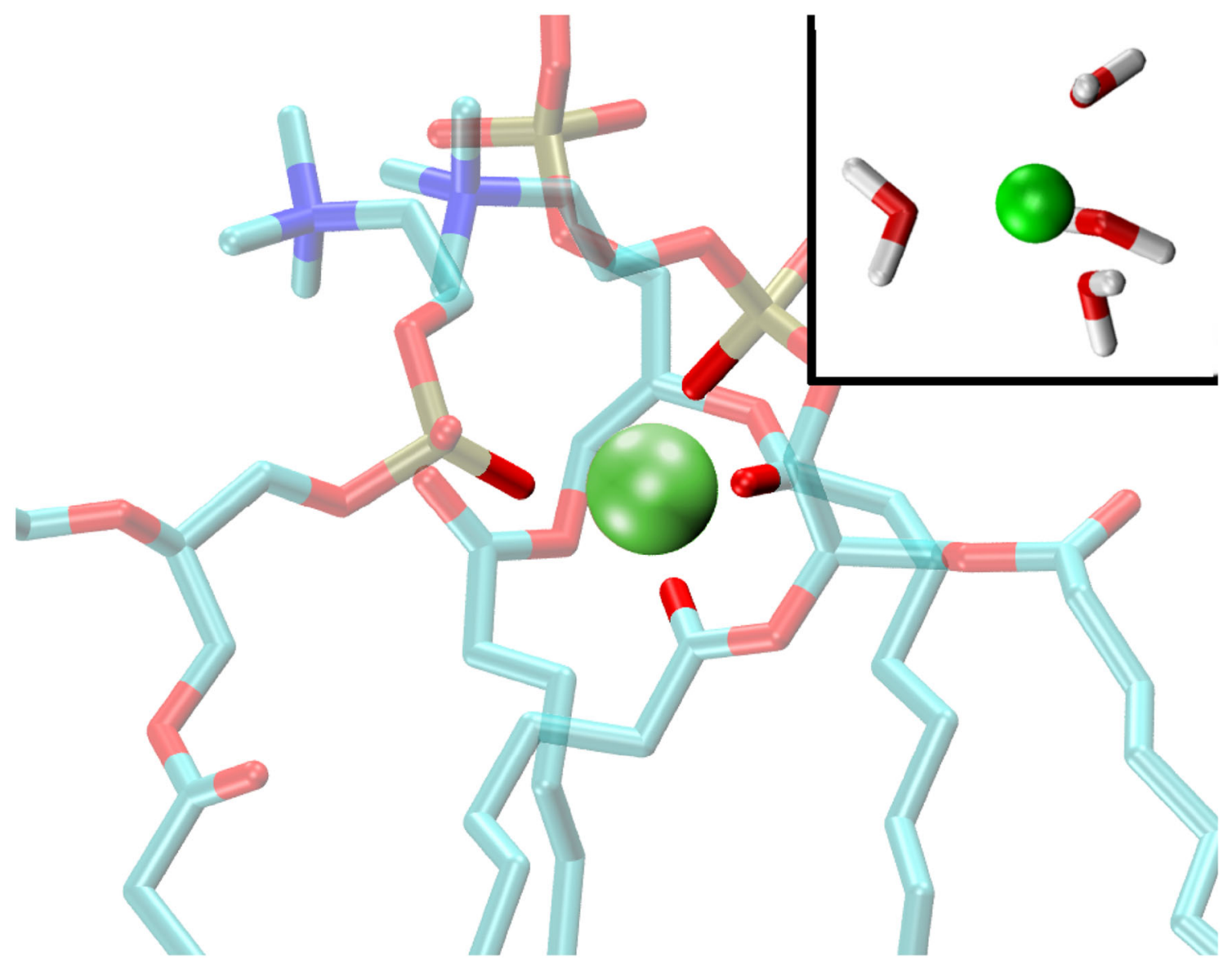

Fig. 2 Snapshot of a common conformation observed in molecular dynamics simulations of lithium ion coming out of aqueous solution and interacting with a POPC membrane (Kruczek et al. 2017). The lithium ion has induced formation of a tetrahedral shell involving a phosphate group and an sn-2 carbonyl group from one phospholipid molecule plus an sn-2 carbonyl from a second phospholipid and a phosphate group from a third phospholipid. Larger alkali metal ions

significantly (McQuillin et al. 2007), to be expected due to the large number of transcription factors regulated by GSK3B. Small molecule inhibitors of GSK3 are effective in the micromolar range (Coghlan et al. 2000), while lithium effects are significant only at much higher concentrations. Mice heterozygous for GSK3B exhibit similar behavioral traits to wild type littermates treated with $1 \mathrm{mM}$ lithium (a concentration that inhibits about $25 \%$ of GSK3 activity, in line with 1 of the 4 alleles of GSK3 inactivated in the GSK3B heterozygous mice) (O'Brien et al. 2004).

For all of the widely-noted importance of the interaction between GSK3 and lithium, the precise biophysics of this interaction is not completely understood. A complicating factor is that GSK3's mode of action involves an interaction with ATP. ATP is associated with $\mathrm{Mg}++$ and with $\mathrm{Li}+$, while $\mathrm{Mg}++$ is also an essential cofactor of GSK3. Combining these factors with the propensity of $\mathrm{Li}+$ to such as sodium or potassium are found to induce this structure only rarely or not at all. The tetrahedral cage geometry in the membrane mimics the tetrahedral geometry of the first shell of hydration waters for the lithium ion in solution (seen in upper right). While lithium commonly has a four-fold coordination in its inner hydration shell, sodium and potassium have six and seven, respectively (Mähler and Persson 2011)

compete with $\mathrm{Mg}++$ for ionic binding sites, the full story appears to be sufficiently complicated to pose a significant challenge to current computational and experimental methods of elucidating biomolecular structure and function.

It should be noted that lithium also inhibits the activity of GSK3 by a second method in addition to competition with magnesium, that is, by increasing phosphorylation (Jope 2003). It appears likely that this effect is secondary to direct lithium inhibition of a phosphatase. In addition to inhibiting the activity of GSK3B, lithium also inhibits its transcription (Mendes 2009).

Of all kinases, GSK3 appears to have the largest number of known substrates, over 100 known (Beurel et al. 2015) and about 500 predicted by theory based on scanning and interpreting relevant motif sequences in the human genome (Linding et al. 2007). Lithium will thus to some extent 
modulate activity along all pathways containing the hundreds of GSK3 substrates. Any comprehensive understanding of lithium action therefore can't just be a summation of actions on individual molecules, but rather must include genome-wide systems understanding of how the action of lithium, through inhibition of GSK3, modulates the activity of the hundreds of substrates regulated by GSK3.

Figure 3 shows graphically 265 proteins that interact directly with GSK3B at a 70\% confidence level, as tabulated in the STRING protein-protein interaction database (Szklarczyk et al. 2016). An exact protocol for replicating the search that resulted in this figure and in calculated enriched gene ontology categories and KEGG pathways for this network of genes are given in supplementary material.

Since lithium affects other magnesium-dependent proteins, the output from the STRING search provides a minimal assessment of lithium effects on biological processes and pathways. There are estimated to be over three thousand human proteins with magnesium binding sites (Piovesan et al. 2012).

\section{Lithium and Mitochondria}

Compared to the cytosol, mitochondria contain much higher levels of active (unphosphorylated) GSK3B (Bijur and Jope 2003), suggesting that mitochondrial function may be especially sensitive to lithium levels. There is also substantial evidence that mitochondrial damage and dysfunction are associated with both affective disorders (Rezin et al. 2009; Manji et al. 2012) and neurodegenerative disease (Lin and Flint Beal 2006). Thus, the question: To what extent are effects of lithium on affective disorders and neurodegeneration due to effects of lithium on mitochondrial function?

One relevant study showed that both lithium and the mood stabilizer valproate have protective effects against amphetamine-induced mitochondrial dysfunction in rats (Valvassori et al. 2010; Bachmann et al. 2009). An increase in complex I and complex II activities of the mitochondrial respiratory chain was shown to be induced by lithium at therapeutic concentrations in human cortical brain tissue, thus suggesting a potential of lithium to enhance oxidative phosphorylation (Maurer et al. 2009). A non-invasive study on human bipolar patients found that treatment with lithium reduced plasma levels of oxidative stress markers (Machado-Vieira et al. 2007), consistent with the more invasive studies.

In addition to affective disorders and neurodegeneration, GSK3B in mitochondria is deeply involved in the antiapoptotic phenotype that characterizes cancer cells (Beurel and Jope 2006; Rasola and Chiara 2013).

\section{Lithium as a Nutrient and a Toxin}

Because of its ubiquity in our environment, ingestion of lithium in at least trace amounts is unavoidable. Based on experiments in which animals are deliberately lithiumdeprived and suffer a decline in fertility, lithium is probably an essential trace element in the diet (Anke et al. 1991; Pickett and O'Dell 1992; Schrauzer 2002). At the other extreme, lithium sufficient to raise plasma levels to above approximately $1.2 \mathrm{mM}$ will cause acute toxicity (Malhi et al. 2011) (nausea, diarrhea, extreme trembling). Above $2 \mathrm{mM}$, death may occur. At levels maintained over years in lithium therapy for bipolar disorder (usually $0.5-0.8 \mathrm{mM}$ ), there appear to be statistically significant chronic problems with renal function, thyroid function, and parathyroid function (McKnight et al. 2012). These problems can generally be managed and are far less debilitating than untreated or ineffectively treated bipolar disorder (Malhi and Berk 2012). Based on epidemiological studies, it appears that sub- therapeutic levels of lithium may have a beneficial effect on mood disorders. Multiple independent studies based on populations from different parts of the world have explored the statistical relationship between lithium concentration in drinking and per capita rate of suicide. Most of these studies have found that the more lithium in the drinking water, the lower the suicide rate (Schrauzer and Shrestha 1990; Ohgami et al. 2009; Helbich et al. 2012; Giotakos et al. 2013; Blüml et al. 2013; Kapusta et al. 2011). One study has found an inverse correlation between lithium in the drinking water and homicide rates (Giotakos et al. 2015). More broadly, one study finds an inverse correlation between lithium concentration in drinking water and age adjusted mortality from all causes, even excluding suicide (Zarse et al. 2011). By contrast, some environmental toxicologists seem to view lithium in ground water solely as a pollutant (Aral and Vecchio-Sadus 2008). Indeed, it would be naïve to leap to a conclusion that more lithium in drinking water is either beneficial or harmful in every way, since lithium has so many diverse effects. One possible point of concern is pregnant women, since epidemiological studies have found reduced thyroid function during pregnancy (Harari et al. 2015) and reduced birth weight (Harari et al. 2015), with higher concentrations of lithium in drinking water.

The wide range of lithium concentrations between background from drinking water and food on the one hand, and therapeutic doses for bipolar disorder on the other hand, remain almost totally unexplored. One multi-year study of low dose lithium (lithium blood concentration $0.25-0.5 \mathrm{mM}$ ), found no evidence of reduced renal function (Aprahamian et al. 2014). 


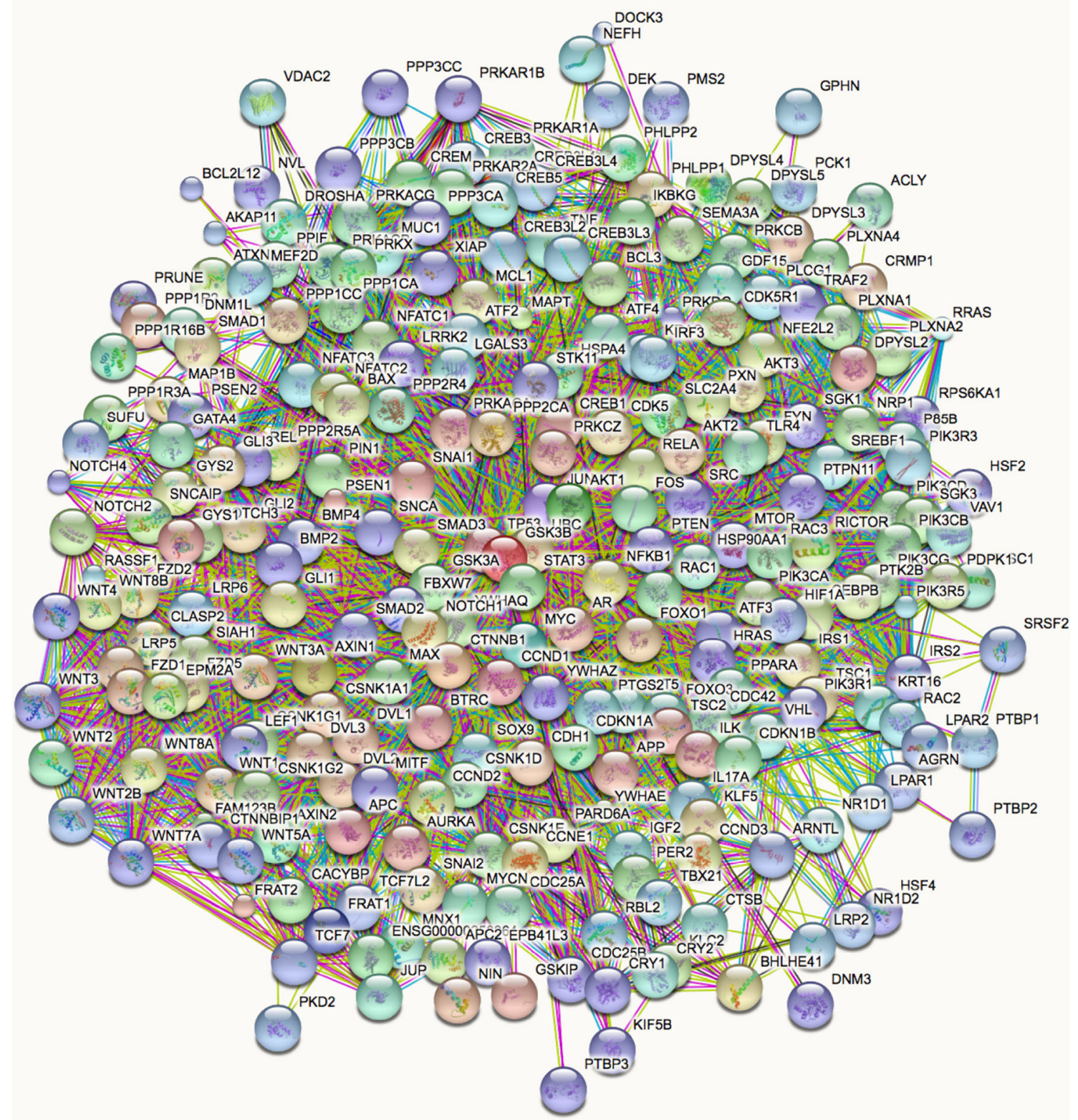

Fig. 3 Interaction diagram for GSK3B and the 265 other proteins with which it interacts directly with $70 \%$ confidence, based on the STRING protein-protein interaction database. Protocol for replicating

\section{Lithium and Affective Disorders}

The clinical history of lithium for the treatment of affective disorders began with the 1949 report by John Cade that he had successfully treated ten manic patients with lithium (Cade 1949). Subsequent experiments scaled Cade's observations to many more subjects (Baastrup and Mogens 1967; Schou 1968). Today, the guidelines of major international psychiatric associations recommend lithium as a first-line therapy for bipolar disease, including the American Psychiatric Association (American Psychiatric Association 2002), The World Federation of Societies of the search for an up-to-date version of this network is provided in Supplementary Material

Biological Psychiatry (Grunze et al. 2004), the Canadian Network for Mood and Anxiety Treatments (CANMAT) (Yatham et al. 2013) and the International Society for Bipolar Disorders (ISBD) (Yatham et al. 2013).

The serotonin theory of depression was suggested by animal experiments using tricyclic antidepressants (de Montigny and Aghajanian 1978) and confirmed by lithium animal experiments (Treiser et al. 1981) and clinical experience (Souza and Goodwin 1991). This theory (Price et al. 1990), combined with the goal of greater specificity of action than provided by lithium or other antidepressants, led to Prozac and the family of selective serotonin reuptake 
inhibitors (SSRI's) — not only a medical but also a cultural revolution (Kramer 1993). In addition to lithium's primary role in treating bipolar disorder, it is also useful as an augmentation to other antidepressants in treatment of unipolar depression (Crossley and Bauer 2007; Nelson et al. 2014). Lithium is the most successful among all antidepressants and mood stabilizing drugs in preventing suicide (Bschor 2014; Cipriani et al. 2013).

Experiments have been reported on the efficacy of administering lithium to inhibit aggressive behavior in inmates of penal institutions (Sheard 1971) and residents of psychiatric hospitals (Craft et al. 1987; Campbell et al. 1995). In each case, it was reported that individuals receiving lithium exhibited less aggressive behavior than individuals in a control group.

Progress has been made in identifying the specific genes and pathways underlying affective disorders, and how lithium modulates at the molecular level. One such gene, originally identified by patterns of mutations in human families, is Disrupted in Schizophrenia-1 (DISC1) (Porteous et al. 2011), in turn regulated by Dixdc1 (Singh et al. 2010). Dixdc1-knockout mice demonstrate behaviors interpreted as mouse versions of human affective disorders, which behaviors are reversed by lithium, presumably by lithium's inhibition of GSK3B (Martin et al. 2016).

\section{Lithium, GSK3, BDNF-Connecting the Dots Between Lithium, Stress, Affective Disorders, and Neurodegenerative Disease}

Reduced serum levels of brain-derived neurotrophic factor (BDNF) have been implicated in depression (Karege et al. 2002), bipolar disorder (Cunha et al. 2006; Post 2007), and dementia (Weinstein et al. 2014). GSK3B inhibits BDNFinduced signaling (Mai et al. 2002). Since lithium inhibits GSK3, it might be expected that lithium would enhance BDNF activity. Indeed, in animal experiments, lithium was shown to enhance the expression of brain-derived BDNF (al 2002). In addition, BDNF has been shown to play an important role in survival of adult and developing central neurons both in culture and in vivo (Berton et al. 2006; Ghosh et al. 1994; Acheson et al. 1995; Conover et al. 1995; Jones et al. 1994). The role of lithium in increasing expression of BDNF plus the role of BDNF in survival of neurons has led to the suggestion that lithium might have a role to play in the treatment of neurodegenerative disease (Chuang 2004).

Several other reported research results have supported the potential of lithium for treatment of neurodegenerative disease, as reviewed by Forlenza et al. (Forlenza et al. 2014). However, relevant clinical trials remain to be done. A major issue is that, because neurodegeneration takes place over several years, the most significant clinical trials would need to involve lithium treatment for a significant number of years, with long-term follow-up of the subjects. The only substantial population of long-term lithium users consists of people who are receiving lithium treatment for bipolar disorder. Not all bipolar patients receive lithium, so one can gather statistics about the incidence of neurodegenerative disease among elderly bipolar patients who have received long-term lithium treatment, and those who have not. In one such study, in an otherwise well-matched cohort of elderly (approximately 70 years old), $5 \%$ of those on long-term lithium therapy (continuous for the previous five years) were diagnosed with Alzheimer's disease (AD), while $33 \%$ of those not receiving consistent lithium therapy were diagnosed with AD (Nunes et al. 2007).

Another type of long-term study is epidemiological. A recent nationwide study in Denmark showed that lithium level in the drinking water was significantly correlated with incidence of dementia, with higher lithium levels showing lower levels of dementia (Kessing et al. 2017).

The early stage of frontotemporal dementia (FTD) typically involves behavior resembling an affective disorder (Woolley et al. 2011), posing a challenge for diagnosis. When FTD is suspected, a definitive diagnosis in the early stage of the disease requires neuroimaging (McMillan et al. 2014). It is generally believed that such a diagnosis, when correct, is a death sentence, typically over a period of 2 to 14 years. However, there may be one documented apparent exception to the incurability of FTD, in a case history presented by Monji et al. (2014). In this study a middleaged man presented affective symptoms that had no apparent origin in early life. Imaging revealed abnormalities typical of FTD. Therefore, a diagnosis of FTD was made. However, because the psychiatric symptoms had a pattern like bipolar disease, lithium therapy was begun. In a little under 2 years the psychiatric symptoms had been completely mitigated and new brain images appeared normal. The authors concluded that the initial diagnosis of FTD was in error. However, the data presented in the paper were also consistent with the hypothesis that the FTD diagnosis was correct and that the lithium therapy reversed the course of the disease. We corresponded with Dr Monji and he agreed via e-mail that this hypothesis is also consistent with the evidence underlying the report from him and his collaborators. If this interpretation is correct, it would provide a counter-indication to the prevailing belief that FTD is invariably fatal. The efficacy of lithium for FTD patients is to be tested in a newly announced clinical trial (https://clinicaltrials.gov/ct2/show/NCT02862), although only with respect to relief of behavioral symptoms over the course of a 12-week trial. The limited scope of this study is a continuation of a line of thought that 
considers affective and neurodegenerative symptoms of FTD as relatively separate (Huey et al. 2006).

Response to stress is not a disorder but rather an adaptive response to an environmental challenge, mediated by release of glucocorticoids (Sapolsky et al. 2000). However stressful events can also cause maladaptive responses, including major episodes of depression (Hammen 2005). In an animal model for stress-induced depression, the induction of depression was found to be facilitated by activity of GSK3B and blocked by lithium (Silva et al. 2008). One possible mechanism for induction of depression by stress is inhibition of adult hippocampal neurogenesis, in response to glucocorticoids (Snyder et al. 2011). Lithium was found to counter the effects of glucocorticoids on adult hippocampal neurogenesis (Boku et al. 2009).

\section{Lithium and Cancer}

Using lithium, GSK-3 inhibition has been shown specifically to inhibit prostate tumor growth (Mazor et al. 2004).

Table 1 shows the 13 KEGG pathway categories that are most statistically enriched in the 265 genes shown in Fig. 3 that are the direct interactors with GSK3B. This table was generated using the analysis tools built into the STRING protein-protein interaction web site. All of these pathways are implicated in cancer. The Wnt signaling pathway (second on the list) is implicated in both cancer (Anastas and Moon 2013; Duffy et al. 2016) and neurodegenerative disease (De Ferrari et al. 2003). The extremely low false discovery rates show that these statistical enrichments could not have occurred by chance, implying that the lithium effect on these pathways, exerted through its inhibition of GSK3B, indeed has significant implications for cancer incidence and therapy.

The possible use of lithium as an anticancer agent is reinforced by a retrospective study showing that psychiatric patients undergoing lithium therapy for bipolar disorder had a much lower incidence of cancer than a matched group not receiving lithium therapy (Cohen et al. 1998). More recent studies of similar design, one conducted nationwide across Sweden, and another across Taiwan, achieved the same result (Martinsson et al. 2016; Huang et al. 2016). On the other hand another nationwide study, this time from Denmark, showed no correlation of lithium with colorectal adenocarcinoma (Pottegård et al. 2016). On closer look, the Denmark study does not contradict the Swedish study. The Swedish study also found that for the entire population lithium was not correlated with cancer incidence, but in addition found that bipolar individuals not treated with lithium had a higher incidence of cancer than the general population. Lithium-treated bipolar patients, on
Table 1 The 13 KEGG pathways most enriched in the 265 genes that interact directly with GSK3B

\begin{tabular}{llll}
\hline Pathway ID & Pathway description & Gene count & FDR \\
\hline 05200 & Pathways in cancer & 77 & $1.86 \mathrm{e}-74$ \\
04310 & Wnt signaling pathway & 54 & $4.78 \mathrm{e}-65$ \\
05166 & HTLV-1 infection & 65 & $6.33 \mathrm{e}-65$ \\
04390 & Hippo signaling pathway & 46 & $1.4 \mathrm{e}-49$ \\
05205 & Proteoglycans in cancer & 52 & $2.36 \mathrm{e}-49$ \\
05161 & Hepatitis B & 45 & $2.97 \mathrm{e}-49$ \\
04151 & Pl3K-Ak1 signaling pathway & 59 & $2.97 \mathrm{e}-49$ \\
05215 & Prostate cancer & 38 & $2.97 \mathrm{e}-49$ \\
05217 & Basal cell carcinoma & 32 & $2.97 \mathrm{e}-49$ \\
05203 & Viral carcinogenesis & 45 & $1.28 \mathrm{e}-43$ \\
05213 & Endometrial cancer & 28 & $5.89 \mathrm{e}-39$ \\
04916 & Melanogenesis & 34 & $9.16 \mathrm{e}-39$ \\
05210 & Colorectal cancer & 29 & $9.16 \mathrm{e}-39$ \\
\hline All &
\end{tabular}

All of these pathways are implicated in cancer. The false discovery rates show that the probability that the degrees of enrichment observed could have occurred by chance, is vanishingly small. Protocol for replicating this search in the STRING database is provided in Supplementary Material

the other hand, had essentially the same cancer incidence as the general population.

A detailed study of molecular mechanisms by which lithium inhibition of GSK3-beta inhibits proliferation of prostate tumor cells in culture was presented by Sun et al. (Sun et al. 2007). The work was subsequently extended to an animal model (Zhu et al. 2011). A clinical trial for the effect of lithium coupled with prostatectomy on men has been conducted, but results not yet published (https://clin icaltrials.gov/ct2/show/NCT02198).

Lithium has been found to be lethal to neuroblastoma cells but not to normal nerve cells (Duffy et al. 2014). The experimentally determined effective dose was $12 \mathrm{mM}$, a level which would be lethal if achieved systemically in a human or model organism but perhaps could be induced locally. A similar effect was found in ovarian cancer cells (Cao et al. 2006), although a subsequent similar study on ovarian cancer cells suggests only a more modest benefit (Novetsky et al. 2013). It is not clear from our reading of the two ovarian cancer papers why the results are significantly different from each other.

With respect to other cancers, one study suggests that lithium inhibits proliferation of a colorectal cancer cell line ( $\mathrm{Li}$ et al. 2014). Another study on colon cancer cells showed that lithium specifically induced a reversal of the epithelial-to-mesenchymal transition characteristic of the cancer cells (Costabile et al. 2015). 
Two studies with relatively small sample size suggested a possible link between lithium and tumors of the upper urinary tract (Rookmaaker et al. 2012; Zaidan et al. 2014). However a large-scale study involving all urinary tract cancers in Denmark over a multi-year period found no correlation with lithium use (Pottegård et al. 2015).

Because lithium therapy is systemic rather than topical or local, it follows that lithium might inhibit metastasis. Evidence that this is the case for colon cancer comes from observation of inhibition of metastasis-inducing factors by lithium and by observation on reduced metastasis in model animals given lithium therapy (Maeng et al. 2016).

\section{Lithium in the Model Eukaryote Yeast}

In the belief that yeast would be a useful model eukaryotic organism, the yeast genome sequence was completed in 1996 (Goffeau et al. 1996). This belief has been amply justified in the intervening years, notably by the award of the 2016 Nobel Prize in Medicine to Yoshinori Ohsumi for his discoveries of mechanisms of autophagy, initially conducted in yeast and then extended to humans and other metazoan (Levine and Klionsky 2017). The yeast genome is rich in homologs of the lithium-sensitive mammalian enzymes mentioned earlier in this review. It thus may be that comparative molecular research with yeast and animal cells and organisms can provide new understandings.

An early general description of the effects of lithium on yeast was made by Asensio et al. (Asensio et al. 1976). Different strains have different levels of sensitivity (Petrezselyova et al. 2010). Studies on yeast halotolerance revealed that Met22p/Hal2p, a conserved adenosine 3,5bisphosphonate phosphatase which can be inhibited by submillimolar concentrations of lithium (IC50 $0.1 \mathrm{mM}$ ), conferred lithium resistance when overexpressed (Murguia et al. 1995). Once Met22/Hal2 is inactivated, adenosine bisphosphonates accumulate leading to the inhibition of sulfotransferases and RNA processing enzymes such as exoribonuclease Xrn1p (Dichtl et al. 1997). The structure of Hal2p has been determined (al 2000) and found to be structurally related to the human BPntase/RnPIP which presents a similar behavior towards lithium (al 2005). Comparative studies across multiple organisms revealed a similar tertiary structure for several phosphomonoesterases involved in inositol signaling, gluconeogenesis, sulfate assimilation, and quinone metabolism, including an ionbinding consensus sequence (D-Xn-EE-Xn-DP(i/l)D(s/g/ a)T-Xn-WD-X11-GG) which is required for catalysis and could be the potential docking site for lithium (York et al. 1995).

Among the family of related phosphomonoesterases, inositol monophosphatase (IMPase) from both yeast and from mammalian brain can be inhibited in vitro at concentrations used to treat bipolar disease (0.5 to $1.0 \mathrm{mM}$ ) (Hallcher and Sherman 1980; Lopez et al. 1999). The inactivation of IMPase blocks the production of inositol from inositol monophosphate (IMP), shutting down the biosynthetic pathway that leads to the generation of inositol-1,4,5 trisphosphate (IP3), a central molecule for several signaling cascades (Berridge 2016). A peculiar feature of lithium-caused inositol depletion is a positive feedback mechanism, in which the incremental effect of lithium is greater the higher the concentration of the IMP-IMPase complex (Berridge et al. 1989). Theory of dynamical systems shows that positive feedback loops create bistable or multistable states (Cinquin and Demongeot 2002). The dramatic and persistent affect shifts in bipolar disorder, and the dramatic change upon treatment with lithium (https:// www.nimh.nih.gov/health/topics/bipolar-disorder/index.shtml), suggest multistable states in the biochemical networks underlying bipolar disorder, possibly related to the inositol depletion positive feedback loop, and other positive feedback loops yet to be identified. The depletion of inositol has been confirmed in organisms as diverse as Xenopus embryos and Dictyostelium (Maslanski et al. 1992; al 1996). However, because of lithium's diverse targets, for example GSK3 as well as IMPase inhibition, no lithium-induced phenotype may be ascribed to any one of lithium's molecular actions without specific controls. Alternatives to the "inositol depletion hypothesis" have been presented for lithium's effects on development (Klein and Melton 1996) and on affective disorders and neurodegenerative disease (Harwood 2005). Because lithium has so many targets, it should be expected in general that no specific modulator of any gene or gene product will completely emulate lithium.

The observation that yeast cells are very sensitive to lithium when grown on galactose, led to the identification of phosphoglucomutase as another lithium target (Masuda et al. 2001). This key enzyme in the sugar metabolism converts glucose-1-phosphate into glucose-6-phosphate. Importantly, yeast (IC50-0.2 mM) and human (IC50-1.5 mM) phosphoglucomutase can be significantly inhibited by lithium in vivo (Csutora et al. 2005). In yeast cells grown on galactose this leads to the accumulation of glucose 1-phosphate and galactose 1-phosphate which impact the balance of trehalose and glycogen, the carbohydrates used for energy storage in yeast (Bro et al. 2003). The overexpression of phosphoglucomutase Pgm2p was shown to rescue lithium sensitivity in galactose medium (Masuda et al. 2001). This discovery shows that some lithium targets can only be revealed by analyzing the behavior of yeast cells in conditions other than growth on rich media. For instance, under starvation conditions, yeast cells trigger a differentiation pathway that leads to meiosis 
and gametogenesis (van Werven and Amon 2011). Interestingly, it was early noticed that gametogenesis in yeast is more sensitive to lithium than normal proliferation (Asensio et al. 1976). We have reproduced this result (unpublished), but the mechanism responsible for the inhibition of gametogenesis is still not clarified. A similar result has been observed in the slime mold Dictyostelium (Maeda 1970). The yeast homolog of the mammalian lithium-sensitive GSK3B, Rim11p, is a major regulator of meiotic entry (Rubin-Bejerano et al. 2004; Bowdish et al. 1994), and could therefore be a target of lithium during gametogenesis. Due to the number of enzymes upregulated during the meiotic differentiation program, other meiosisspecific proteins could also be lithium sensitive.

In yeast as in mammals, membrane mechanisms that transport sodium also transport lithium (Wieland et al. 1995; Ariño et al. 2010). Yeast extrudes both sodium and lithium through the NHA1 proton-sodium antiporter (Prior et al. 1996) and through the PMR2/ENA family of ATPases (Ruiz and Arino 2007). Experiments comparing lithium sensitivity of haploid vs. diploid yeast cells showed that deletion of the ENA transporters, leaving presumably only NHA1 to export lithium, produced yeast cells many times more sensitive to lithium than the wild type (Zörgö et al. 2013). The wide range of lithium sensitivity in yeast strains observed by Petrezselyova et al. (Petrezselyova et al. 2010) might be explained by different patterns of sodium transporter expression and density at the cell membrane. Based on BLAST against the human proteins, the yeast PMR/ENA family members are part of a larger family shared with humans of cation-transport ATPases. NHA1, however, does not appear to be closely related to any of the human sodium-proton antiporters, neither the human NHE family (Orlowski and Grinstein 2004) nor to human NHA2 (Fuster et al. 2008).

Because of the high degree of orthology between mammalian lithium-sensitive magnesium-dependent enzymes and their yeast counterparts, it is reasonable to expect that the lithium sensitivity of biochemical pathways will be found to be based on the antagonism between $\mathrm{Li}+$ and $\mathrm{Mg}++$. Experimentally this is so far supported. The lithium inhibition on phosphoglucomutase can be relieved by high magnesium concentrations (Masuda et al. 2001). Referring to a cellular phenotype, yeast gametogenesis is promoted by $\mathrm{Mg}++$ (Suizu et al. 1994) but inhibited by $\mathrm{Li}+$ (Asensio et al. 1976).

In summary, in yeast as in mammalian cells, lithiumsodium competition for membrane transport modulates the intracellular lithium concentration, and lithium-magnesium competition for binding sites in enzymes modulates the biochemical phenotype. It appears that the yeast is a useful model system for understanding lithium effects in eukaryotes.

\section{Origins and Evolution of Lithium in Biology}

It is a prevalent view that a precursor to the emergence of biochemistry as we know it consisted of networks of replicating RNA molecules (Higgs and Lehman 2015). An essential component of the RNA world would have been the oligomerization of RNA molecules into long enough molecules to have distinctive identities, one from the other. In one possible scenario this was catalyzed on clay surfaces with small ions such as lithium and sodium as essential co-factors (Joshi and Aldersley 2013; Ferris 2005).

Only a few studies have been done on either the organismic or the biochemical response of prokaryotes to lithium. One such study found that gram-positive bacteria can take up much more lithium from an aqueous medium than yeast or other fungi, so we know there are pathways for entry (Tsuruta 2005).

In the absence of direct experimental data, sequence homologies and orthologies can at least provide plausible hypotheses about the extent to which eukaryotic lithium transport mechanisms and lithium-sensitive enzymes are also present in bacteria. Presumably significant paths of lithium entry into bacteria are by sodium channels (Koishi et al. 2004) and pentameric ligand-gated channels (Tasneem et al. 2004) orthologous to the corresponding metazoan channels that have been shown to be $\mathrm{Li}+$-permeable (Richelson 1977; Krishnamurthy et al. 2009; Grosman, Claudio 2016. Personal communication based on unpublished observations). Based on a sequence search for orthologs in the Uniprot database (unpublished), it appears that the NHA1 proton-sodium antiporter that extrudes lithium from the yeast cell has orthologs in bacteria, so this may be a common path for lithium to leave. The sodiumproton antiporter that enables export of lithium in metazoan cells (Busch et al. 1995), has numerous orthologs in both bacteria and archaea, with the transport function verified experimentally (Rahav-Manor et al. 1992). On the other hand, reciprocal BLAST by us (unpublished) finds that the closest bacterial homologs to the yeast ENA sodium transporter are orthologous to yeast calcium transporters, so it may be that this mechanism for lithium export is uncommon or lacking in bacteria.

Orthologs to the magnesium-dependent lithium-sensitive eukaryotic protein kinases are abundant in bacteria and archaea (Leonard et al. 1998). Bacteria also contain members of the magnesium-dependent lithium-sensitive phosphomonoesterase family (York et al. 1995).

It appears that lithium has had a significant effect on first molecular and then biological evolution, and that major elements of lithium transport and modulation of biochemical function are shared across all classes of living systems. 


\section{Summary}

- Many aspects of the distribution of lithium within cells and extracellular fluid are due to competition of lithium with sodium for sites in transporters and channels that are primarily sodium-selective. Much remains to be learned about the details of this competition.

- Many biochemical effects of lithium are due to competition of lithium with magnesium for sites in biomolecules that are primarily magnesium-selective. Much remains to be learned about the details of this competition. Much also remains to be learned about how the multiple molecular targets of lithium, and the many more substrates of lithium targets, interact to modulate the integrated behavior of cells.

- Few studies have been done on the effect of lithium on membranes. Those studies suggest significant effects of lithium on local membrane structure and on distribution of signaling proteins between rafts and fluid regions of membranes.

- Levels of ingested lithium appear to have profound effects on human well-being across the spectrum of normal health, and susceptibility to important diseases, such as mood disorders, neurodegenerative disease, and cancer. Much remains to be learned and understood about the biochemistry underlying the full range of these effects and the implications of that biochemistry for nutrition and medicine. Such explorations will be aided by the fact that the many and widely varying effects of lithium seem to be caused by only a small number of underlying biophysical mechanisms. On the other hand, the widespread nature of the effects requires the application of the tools and approach of systems biology, which has so far been done only in a very preliminary way.

Open Access This article is distributed under the terms of the Creative Commons Attribution 4.0 International License (http://crea tivecommons.org/licenses/by/4.0/), which permits unrestricted use, distribution, and reproduction in any medium, provided you give appropriate credit to the original author(s) and the source, provide a link to the Creative Commons license, and indicate if changes were made.

\section{References}

Acheson A, Conover JC, Fandl JP, DeChiara TM, Russell M, Thadani A, Squinto SP, Yancopoulos GD, Lindsay RM (1995) A BDNF autocrine loop in adult sensory neurons prevents cell death. $450-453$

Albert A et al (2000) X-ray structure of yeast Hal2p, a major target of lithium and sodium toxicity, and identification of framework interactions determining cation sensitivity. J Mol Biol 295(4):2. doi:10.1006/jmbi.1999.3408
American Psychiatric Association (2002) Practice guideline for the treatment of patients with bipolar disorder (revision). Am J Psychiatr 159(4 Suppl):1

Anastas JN, Moon RT (2013) WNT signalling pathways as therapeutic targets in cancer. Nat Rev Cancer 13(1):11-26

Anke M, Arnhold W, Groppel B, Krause U (1991) The biological importance of lithium. Lithium Biol Med 149-167

Aprahamian I, Santos FS, dos Santos B, Talib L, Diniz BS, Radanovic M, Gattaz WF, Forlenza OV (2014) Long-term, low-dose lithium treatment does not impair renal function in the elderly: a 2-year randomized, placebo-controlled trial followed by singleblind extension. J Clin Psychiatr 75(7):672-678

Aral H, Vecchio-Sadus A (2008) Toxicity of lithium to humans and the environment-a literature review. Ecotoxicol Environ Saf 70.3:349-356

Ariño J, Ramos J, Sychrová H (2010) Alkali metal cation transport and homeostasis in yeasts. Microbiol Mol Biol Rev 74(1): 95-120

Asensio J, Ruiz-Argueso T, Rodriguez-Navarro A (1976) Sensitivity of yeasts to lithium. Antonie Van Leeuwenhoek 42(1-2):1-8

Kessing LV, Gerds TA, Knudsen NN, Jørgensen LF, Kristiansen SM, Voutchkova D, Ernstsen V, Schullehner J, Hansen B, Andersen PK, Ersbøll AK (2017) Association of lithium in drinking water with the incidence of dementia. JAMA Psychiatry 74(10): $1005-1010$

Avissar S, Murphy DL, Schreiber G (1991) Magnesium reversal of lithium inhibition of $\beta$-adrenergic and muscarinic receptor coupling to G proteins. Biochem Pharmacol 41(2):171-175

Ayotte JD, Gronberg JM, Apodaca LE (2011) Trace elements and radon in groundwater across the United States, 1992-2003. US Department of the Interior, US Geological Survey

Baastrup PC, Mogens S (1967) Lithium as a prophylactic agent: its effect against recurrent depressions and manic-depressive psychosis. Arch Gen Psychiatr 16(2):162-172

Bachmann RF, Wang Y, Yuan P, Zhou R, Li X, Alesci S, Jing D, Manji HK (2009) Common effects of lithium and valproate on mitochondrial functions: protection against methamphetamineinduced mitochondrial damage. Int $\mathrm{J}$ Neuropsychopharmacol 12(6):805-822

Bauer M, Gitlin M (2016) What is lithium and how does it work? In: The essential guide to lithium treatment. Springer International Publishing, pp 33-43

Beals CR, Sheridan CM, Turck CW, Gardner P, Crabtree GR (1997) Nuclear export of NF-ATc enhanced by glycogen synthase kinase-3. Science 275(5308):1930-1933

Berridge MJ (2016) The inositol trisphosphate/calcium signaling pathway in health and disease. Physiol Rev 96(4):1261-1296. https://doi.org/10.1152/physrev.00006.2016

Berridge MJ, Peter Downes C, Hanley MR (1989) Neural and developmental actions of lithium: a unifying hypothesis. Cell 59(3):411-419

Berton O, McClung CA, DiLeone RJ, Krishnan V, Renthal W, Russo SJ, Graham D et al (2006) Essential role of BDNF in the mesolimbic dopamine pathway in social defeat stress. Science 311(5762):864-868

Beurel E, Jope RS (2006) The paradoxical pro-and anti-apoptotic actions of GSK3 in the intrinsic and extrinsic apoptosis signaling pathways. Prog Neurobiol 79(4):173-189

Beurel E, Michalek SM, Jope RS (2010) Innate and adaptive immune responses regulated by glycogen synthase kinase-3 (GSK3). Trends Immunol 31(1):24-31

Beurel E, Grieco SF, Jope RS (2015) Glycogen synthase kinase-3 (GSK3): regulation, actions, and diseases. Pharmacol Ther 148:114-131 
Bijur GN, Jope RS (2003) Glycogen synthase kinase-3 $\beta$ is highly activated in nuclei and mitochondria. NeuroReport 14(18): 2415-2419

Birch NJ (1974) Lithium and magnesium-dependent enzymes. Lancet 304(7886):965-966

Blüml V, Regier MD, Hlavin G, Rockett IRH, König F, Vyssoki B, Bschor T, Kapusta ND (2013) Lithium in the public water supply and suicide mortality in Texas. J Psychiatr Res 47(3):407-411

Boku S, Nakagawa S, Masuda T, Nishikawa H, Kato A, Kitaichi Y, Inoue T, Koyama T (2009) Glucocorticoids and lithium reciprocally regulate the proliferation of adult dentate gyrus-derived neural precursor cells through GSK-3 $\beta$ and $\beta$-catenin/TCF pathway. Neuropsychopharmacology 34(3):805-815

Boudker O, Ryan RM, Yernool D, Shimamoto K, Gouaux E (2007) Coupling substrate and ion binding to extracellular gate of a sodium-dependent aspartate transporter. Nature 445(7126):387-393

Bowdish KS, Yuan HE, Mitchell AP (1994) Analysis of RIM11, a yeast protein kinase that phosphorylates the meiotic activator IME1. Mol Cell Biol 14(12):1

Boyman L, Williams GS, Khananshvili D, Sekler I, Lederer WJ (2013) NCLX: the mitochondrial sodium calcium exchanger. J Mol Cell Cardiol 59:205-213

Briggs KT, Giulian GG, Li G, Kao JP, Marino JP (2016) A molecular model for lithium's bioactive form. Biophys J 111(2):294-300

Bro C, Regenberg B, Lagniel G, Labarre J, Montero-Lomelí M, Nielsen J (2003) Transcriptional, proteomic, and metabolic responses to lithium in galactose-grown yeast cells. J Biol Chem 278(34):32141-32149

Bschor T (2014) Lithium in the treatment of major depressive disorder. Drugs 74(8):855-862

Busch S, Burckhardt B-C, Siffert W (1995) Expression of the human sodium/proton exchanger NHE-1 in Xenopus laevis oocytes enhances sodium/proton exchange activity and establishes sodium/lithium countertransport. Pflügers Archiv 429(6):859-869

Cade JFJ (1949) Lithium salts in the treatment of psychotic excitement. Med J Aust (1949)

Campbell M, Adams PB, Small AM, Kafantaris V, Silva RR, Shell J, Perry R, Overall JE (1995) Lithium in hospitalized aggressive children with conduct disorder: a double-blind and placebocontrolled study. J Am Acad Child Adolesc Psychiatr 34(4):445-453

Canessa M, Adragna N, Solomon HS, Connolly TM, Tosteson DC (1980) Increased sodium-lithium countertransport in red cells of patients with essential hypertension. $N$ Engl J Med 302(14):772-776

Cao Q, Xin L, Feng Y-J (2006) Glycogen synthase kinase-3 $\beta$ positively regulates the proliferation of human ovarian cancer cells. Cell Res 16(7):671-677

Chuang D-M (2004) Neuroprotective and neurotrophic actions of the mood stabilizer lithium: can it be used to treat neurodegenerative diseases? Crit Rev ${ }^{\mathrm{TM}}$ Neurobiol 16.1\&2

Cinquin O, Demongeot J (2002) Positive and negative feedback: striking a balance between necessary antagonists. J Theor Biol 216(2):229-241

Cipriani A, Hawton K, Stockton S, Geddes JR (2013) Lithium in the prevention of suicide in mood disorders: updated systematic review and meta-analysis. BMJ 346:f3646

Coghlan MP, Culbert AA, Cross DA, Corcoran SL, Yates JW, Pearce NJ, Rausch OL et al (2000) Selective small molecule inhibitors of glycogen synthase kinase- 3 modulate glycogen metabolism and gene transcription. Chem Biol 7(10):793-803

Cohen Y, Chetrit A, Sirota P, Modan B (1998) Cancer morbidity in psychiatric patients: influence of lithium carbonate treatment. Med Oncol 15(1):32-36
Conover JC, Erickson JT, Katz DM, Bianchi LM, Poueymirou WT, McClain J, Pan L et al (1995) "Neuronal deficits, not involving motor neurons, in mice lacking BDNF and/or NT4. 235-238

Costabile V, Duraturo F, Delrio P, Rega D, Pace U, Liccardo R, Rossi GB, Genesio R, Nitsch L, Izzo P, De Rosa M (2015) Lithium chloride induces mesenchymal-to-epithelial reverting transition in primary colon cancer cell cultures. Int $\mathrm{J}$ Oncol 46(5):1913-1923

Craft M, Ismail IA, Krishnamurti D, Mathews J, Regan A, Seth RV, North PM (1987) Lithium in the treatment of aggression in mentally handicapped patients. A double-blind trial. Brit $\mathrm{J}$ Psychiatr 150(5):685-689

Crossley NA, Bauer M (2007) Acceleration and augmentation of antidepressants with lithium for depressive disorders: two metaanalyses of randomized, placebo-controlled trials. J Clin Psychiatr 68(6):935-940

Csaky TZ (1961) Significance of sodium ions in active intestinal transport of nonelectrolytes. Am J Physiol-Leg Content 201(6):999-1001

Csutora P, Strassz A, Boldizsár F, Németh P, Sipos K, Aiello DP, Bedwell DM, Miseta A (2005) Inhibition of phosphoglucomutase activity by lithium alters cellular calcium homeostasis and signaling in Saccharomyces cerevisiae. Am J Physiol Cell Physiol 289(1):C58-C67

Cunha ABM, Frey BN, Andreazza AC, Goi JD, Rosa AR, Gonçalves CA, Santin A, Kapczinski F (2006) Serum brain-derived neurotrophic factor is decreased in bipolar disorder during depressive and manic episodes. Neurosci Lett 398(3):215-219

De Ferrari GV, Chacon MA, Barria MI, Garrido JL, Godoy JA, Olivares G, Reyes AE, Alvarez A, Bronfman M, Inestrosa NC (2003) Activation of Wnt signaling rescues neurodegeneration and behavioral impairments induced by $\beta$-amyloid fibrils. Mol Psychiatr 8(2):195-208

de Montigny C, Aghajanian GK (1978) Tricyclic antidepressants: long-term treatment increases responsivity of rat forebrain neurons to serotonin. Science 202(4374):1303-1306

de Mota de Freitas D, Castro MMCA, Geraldes CF (2006) Is competition between $\mathrm{Li}+$ and $\mathrm{Mg} 2+$ the underlying theme in the proposed mechanisms for the pharmacological action of lithium salts in bipolar disorder? Acc Chem Res 39(4):283-291

de Roos NM, de Vries JHM, Katan MB (2001) Serum lithium as a compliance marker for food and supplement intake. Am J Clin Nutr 73(1):75-79

Dichtl B, Stevens A, Tollervey D (1997) Lithium toxicity in yeast is due to the inhibition of RNA processing enzymes. EMBO J 16(23):7184-7195. doi:10.1093/emboj/16.23.7184

Doble BW, Patel S, Wood GA, Kockeritz LK, Woodgett JR (2007) Functional redundancy of GSK-3 $\alpha$ and GSK-3 $\beta$ in $\mathrm{Wnt} / \beta$ catenin signaling shown by using an allelic series of embryonic stem cell lines. Dev Cell 12(6):957-971

Donahoo WT, Bessesen DH, Higbee DR, Lei S, Grunwald GK, Higgins JA (2004) Serum lithium concentration can be used to assess dietary compliance in adults. J Nutr 134(11):3133-3136

Donati RJ, Schappi J, Czysz AH, Jackson A, Rasenick MM (2015) Differential effects of antidepressants escitalopram versus lithium on Gs alpha membrane relocalization. BMC Neurosci 16(1):40

Duffy DJ, Krstic A, Schwarzl T, Higgins DG, Kolch W (2014) GSK3 inhibitors regulate MYCN mRNA levels and reduce neuroblastoma cell viability through multiple mechanisms, including p53 and Wnt signaling. Mol Cancer Ther 13(2):454-467

Duffy DJ, Krstic A, Schwarzl T, Halasz M, Iljin K, Fey D, Haley B et al (2016) Wnt signalling is a bi-directional vulnerability of cancer cells. Oncotarget 7(37):60310-60331

Ferris JP (2005) Mineral catalysis and prebiotic synthesis: montmorillonite-catalyzed formation of RNA. Elements 1(3):145-149 
Fields BD, Olive KA (2006) Big bang nucleosynthesis. Nucl Phys A 777:208-225

Forlenza OV, de Jesus Rodrigues De Paula V, Diniz BS (2014) Neuroprotective effects of lithium: implications for the treatment of Alzheimer's disease and related neurodegenerative disorders. ACS Chem Neurosci (2014)

Fossel ET, Sarasua MM, Koehler KA (1985) A lithium-7 NMR investigation of the lithium ion interaction with phosphatidylcholine-phosphatidylglycerol membranes. Observation of calcium and magnesium ion competition. J Magn Reson 64(3):536-540

Freland L, Beaulieu J-M (2012) Inhibition of GSK3 by lithium, from single molecules to signaling networks. Front Mol Neurosci 5

Fuster DG, Zhang J, Shi M, Alexandru Bobulescu I, Andersson S, Moe OW (2008) Characterization of the sodium/hydrogen exchanger NHA2. J Am Soc Nephrol 19(8):1547-1556

Ghosh A, Carnahan J, Greenberg ME (1994) Requirement for BDNF in activity-dependent survival of cortical neurons. Science 263(5153):1618-1623

Giotakos O, Nisianakis P, Tsouvelas G, Giakalou (2013) Lithium in the public water supply and suicide mortality in Greece. Biol Trace Elem Res 156(1-3):376-379

Giotakos O, Tsouvelas G, Nisianakis P, Giakalou V, Lavdas A, Tsiamitas C, Panagiotis K, Kontaxakis V (2015) A negative association between lithium in drinking water and the incidences of homicides, in Greece. Biol Trace Elem Res 164(2):165-168

Goffeau A, Barrell BG, Bussey H, Davis RW et al (1996) Life with 6000 genes. Science 274(5287):546

Goldschmidt VM (1937) The principles of distribution of chemical elements in minerals and rocks. The seventh Hugo Müller Lecture, delivered before the Chemical Society on March 17th, 1937. J Chem Soc (Resumed) 655-673

Grimes CA, Jope RS (2001) The multifaceted roles of glycogen synthase kinase $3 \beta$ in cellular signaling. Prog Neurobiol 65(4):391-426

Grunze H, Kasper S, Goodwin G, Bowden C, Moller H-j, WFSBP Task Force on Treatment Guidelines for Bipolar Disorders (2004) The World Federation of Societies of Biological Psychiatry (WFSBP) guidelines for the biological treatment of bipolar disorders, part III: maintenance treatment. World J Biol Psychiatr 5(3):120-135

Haimovich A, Eliav U, Goldbourt A (2012) Determination of the lithium binding site in inositol monophosphatase, the putative target for lithium therapy, by magic-angle-spinning solid-state NMR. J Am Chem Soc 134(12):5647-5651

Hallcher LM, Sherman WR (1980) The effects of lithium ion and other agents on the activity of Myo-Inositol-1-Phosphatase from bovine brain. J Biol Chem 255(22):10896-10901

Hammen C (2005) Stress and depression. Annu Rev Clin Psychol 1:293-331

Harari F, Bottai M, Casimiro E, Palm B, Vahter M (2015) Exposure to lithium and cesium through drinking water and thyroid function during pregnancy: a prospective cohort study. Thyroid

Harari F, Langeén M, Casimiro E, Bottai M, Palm B, Nordqvist H, Vahter M (2015) Environmental exposure to lithium during pregnancy and fetal size: a longitudinal study in the Argentinean Andes. Environ Int 77:48-54

Hardt SE, Sadoshima J (2002) Glycogen synthase kinase-3 $\beta$ a novel regulator of cardiac hypertrophy and development. Circ Res 90(10):1055-1063

Harwood AJ (2005) Lithium and bipolar mood disorder: the inositoldepletion hypothesis revisited. 117-126

Hashimoto R et al (2002) Lithium induces brain-derived neurotrophic factor and activates TrkB in rodent cortical neurons: an essential step for neuroprotection against glutamate excitotoxicity. Neuropharmacology 43.7:1173-1179
Helbich M, Leitner M, Kapusta ND (2012) Geospatial examination of lithium in drinking water and suicide mortality. Int $\mathrm{J}$ Health Geogr 11:19

Higgs PG, Lehman N (2015) The RNA World: molecular cooperation at the origins of life. Nat Rev Genet 16(1):7-17

Hoeflich KP, Luo J, Rubie EA, Tsao MS, Jin O, Woodgett JR (2000) Requirement for glycogen synthase kinase-3beta in cell survival and NF-kappaB activation. Nature 406:86-90

https://clinicaltrials.gov/ct2/show/NCT02198859

https://clinicaltrials.gov/ct2/show/NCT02862210

https://www.nimh.nih.gov/health/topics/bipolar-disorder/index.shtml

Huang R-Y, Hsieh K-P, Huang W-W, Yang Y-H (2016) Use of lithium and cancer risk in patients with bipolar disorder: population-based cohort study. Brit J Psychiatr bjp-bp

Huey ED, Putnam KT, Grafman J (2006) A systematic review of neurotransmitter deficits and treatments in frontotemporal dementia. Neurology 66(1):17-22

Jones KR, Fariñas I, Backus C, Reichardt LF (1994) Targeted disruption of the BDNF gene perturbs brain and sensory neuron development but not motor neuron development. Cell 76(6):989-999

Jope RS (2003) Lithium and GSK-3: one inhibitor, two inhibitory actions, multiple outcomes. Trends Pharmacol Sci 24(9):441-443

Joshi PC, Aldersley MF (2013) Significance of mineral salts in prebiotic RNA synthesis catalyzed by montmorillonite. J Mol Evol 76(6):371-379

Juhaszova M, Zorov DB, Kim S-H, Pepe S, Qin F, Fishbein KW, Ziman BD et al (2004) Glycogen synthase kinase-3 $\beta$ mediates convergence of protection signaling to inhibit the mitochondrial permeability transition pore. J Clin Investig 113(11):1535-1549

Kaczmarek LK (2013) Slack, slick, and sodium-activated potassium channels. ISRN Neurosci (2013)

Kapusta ND, Mossaheb N, Etzersdorfer E, Hlavin G, Thau K, Willeit M, Praschak-Rieder N, Sonneck G, Leithner-Dziubas K (2011) Lithium in drinking water and suicide mortality. Brit J Psychiatr 198(5):346-350

Karege F, Perret G, Bondolfi G, Schwald M, Bertschy G, Aubry J-M (2002) Decreased serum brain-derived neurotrophic factor levels in major depressed patients. Psychiatr Res 109(2):143-148

Klein PS, Melton DA (1996a) A molecular mechanism for the effect of lithium on development. Proc Natl Acad Sci 93(16):8455-8459

Klein PS, Melton DA (1996) A molecular mechanism for the effect of lithium on development. Proc Natl Acad Sci USA 93(16):8455-8459

Koishi R, Haoxing X, Ren D, Navarro B, Spiller BW, Shi Q, Clapham DE (2004) A superfamily of voltage-gated sodium channels in bacteria. J Biol Chem 279(10):9532-9538

Kotyńska J, Dobrzyńska I, Figaszewski ZA (2016) Association of alkali metal cations with phosphatidylcholine liposomal membrane surface. Eur Biophys J 1-7

Kramer PD (1993) Listening to Prozac. Viking, New York

Krishnamurthy H, Piscitelli CL, Gouaux E (2009) Unlocking the molecular secrets of sodium-coupled transporters. Nature 459(7245):347-355

Kruczek J, Chiu S-W, Jakobsson E, Pandit SA (20170 Effects of lithium and other monovalent ions on palmitoyl oleoyl phosphatidylcholine bilayer. Langmuir

Kuo C-C, Hess P (1993) Characterization of the high-affinity Ca2+ binding sites in the L-type $\mathrm{Ca} 2+$ channel pore in rat pheochromocytoma cells. J Physiol 466:657

Leonard CJ, Aravind L, Koonin EV (1998) Novel families of putative protein kinases in bacteria and archaea: evolution of the "eukaryotic" protein kinase superfamily. Genome Res 8(10):1038-1047 
Levine B, Klionsky DJ (2017) Autophagy wins the 2016 Nobel Prize in Physiology or Medicine: breakthroughs in baker's yeast fuel advances in biomedical research. Proc Natl Acad Sci 114(2):201-205

Lewis CA, Stevens CF (1983) Acetylcholine receptor channel ionic selectivity: ions experience an aqueous environment. Proc Natl Acad Sci 80(19):6110-6113

Li H, Huang K, Liu X, Liu J, Lu X, Tao K, Wang G, Wang J (2014) Lithium chloride suppresses colorectal cancer cell survival and proliferation through ROS/GSK-3 $\beta / \mathrm{NF}-\kappa \mathrm{B}$ signaling pathway. Oxid Med Cell Longev

Lin MT, Flint Beal M (2006) Mitochondrial dysfunction and oxidative stress in neurodegenerative diseases. Nature 443(7113):787-795

Linding R, Jensen LJ, Ostheimer GJ, van Vugt MA, Jørgensen C, Miron IM, Diella F et al (2007) Systematic discovery of in vivo phosphorylation networks. Cell 129(7):1415-1426

Lopez F, Leube M, Gil-Mascarell R, Navarro-Aviñó JP, Serrano R (1999) The yeast inositol monophosphatase is a lithium-and sodium-sensitive enzyme encoded by a non-essential gene pair. Mol Microbiol 31(4):1255-1264

Lopez-Corcuera B, Gimenez C, Aragon C (1988) Change of synaptic membrane lipid composition and fluidity by chronic administration of lithium. Biochim Biophys Acta (BBA)-Biomembr 939(3):467-475

MacAulay K, Doble BW, Patel S, Hansotia T, Sinclair EM, Drucker DJ, Nagy A, Woodgett JR (2007) Glycogen synthase kinase 3alpha-specific regulation of murine hepatic glycogen metabolism. Cell Metab 6:329-337

Machado-Vieira R, Andreazza AC, Viale CI, Zanatto V, Cereser V, da Silva R, Vargas FK et al (2007) Oxidative stress parameters in unmedicated and treated bipolar subjects during initial manic episode: a possible role for lithium antioxidant effects. Neurosci Lett 421(1):33-36

Maeda Y (1970) Influence of ionic conditions on cell differentiation and morphogenesis of the cellular slime molds. Dev Growth Differ 12(3):217-227

Maeng Y-S, Lee R, Lee B, Choi S-1, Kim EK (2016) Lithium inhibits tumor lymphangiogenesis and metastasis through the inhibition of TGFBIp expression in cancer cells. Sci Rep 6

Mähler J, Persson I (2011) A study of the hydration of the alkali metal ions in aqueous solution. Inorg Chem 51(1):425-438

Mai L, Jope RS, Li X (2002) BDNF-mediated signal transduction is modulated by GSK $3 \beta$ and mood stabilizing agents. J Neurochem 82(1):75-83

Maity P, Saha B, Suresh Kumar G, Karmakar S (2016) Binding of monovalent alkali metal ions with negatively charged phospholipid membranes. Biochim Biophys Acta (BBA)-Biomembr 1858(4):706-714

Malhi GS, Berk M (2012) Is the safety of lithium no longer in the balance? Lancet 379(9817):690-692

Malhi GS, Tanious M, Gershon S (2011) The lithiumeter: a measured approach. Bipolar Disord 13(3):219-226

Manji H, Kato T, Di Prospero NA, Ness S, Beal MF, Krams M, Chen G (2012) Impaired mitochondrial function in psychiatric disorders. Nat Rev Neurosci 13(5):293-307

Martin PM, Stanley RE, Ross AP, Freitas AE, Moyer CE, Brumback AC, Iafrati J et al (2016) DIXDC1 contributes to psychiatric susceptibility by regulating dendritic spine and glutamatergic synapse density via GSK3 and $\mathrm{Wnt} / \beta$-catenin signaling. Mol Psychiatr (2016)

Martinsson L, Westman J, Hällgren J, Ösby U, Backlund L (2016) Lithium treatment and cancer incidence in bipolar disorder. Bipolar Disord 18(1):33-40

Maslanski JA, Leshko L, Busa WB (1992) Lithium-sensitive production of inositol phosphates during amphibian embryonic mesoderm induction. Science (New York, N.Y.) 256(5054):243-245

Masuda CA, Xavier MA, Mattos KA, Galina A, Montero-Lomelí M (2001a) Phosphoglucomutase is an in vivo lithium target in yeast. J Biol Chem 276(41):37794-37801

Masuda CA, Xavier MA, Mattos KA, Galina A, Montero-Lomelí M (2001) Phosphoglucomutase is an in vivo lithium target in yeast. J Biol Chem 276(41):37794-37801

Maurer IC, Schippel P, Volz H-P (2009) Lithium-induced enhancement of mitochondrial oxidative phosphorylation in human brain tissue. Bipolar Disord 11(5):515-522

Mazor M, Kawano Y, Zhu H, Waxman J, Kypta RM (2004) Inhibition of glycogen synthase kinase-3 represses androgen receptor activity and prostate cancer cell growth. Oncogene 23(47):7882-7892

McKnight RF, Adida M, Budge K, Stockton S, Goodwin GM, Geddes JR (2012) Lithium toxicity profile: a systematic review and meta-analysis. Lancet 379(9817):721-728

McMillan CT, Avants BB, Cook P, Ungar L, Trojanowski JQ, Grossman M (2014) The power of neuroimaging biomarkers for screening frontotemporal dementia. Hum Brain Mapp 35(9):4827-4840

McQuillin A, Rizig M, Gurling H (2007) A microarray gene expression study of the molecular pharmacology of lithium carbonate on mouse brain mRNA to understand the neurobiology of mood stabilization and treatment of bipolar affective disorder. Pharmacogenet Genom 17(8):605-617

Meisel JD, Kim DH (2016) Inhibition of lithium-sensitive phosphatase BPNT-1 causes selective neuronal dysfunction in C. elegans. Curr Biol 26(14):1922-1928

Mendels J, Frazer A (1973) Intracellular lithium concentration and clinical response: towards a membrane theory of depression. J Psychiatr Res 10(1):9-18

Mendes, CT, Mury FB, de Sá Moreira E, Alberto FL, Forlenza OV, Dias-Neto E, Gattaz WF (2009) Lithium reduces Gsk3b mRNA levels: implications for Alzheimer disease. Eur Arch Psychiatr Clin Neurosci 259(1):16-22

Monji A, Motomura K, Mizoguchi Y, Ohara T, Baba S, Yoshiura T, Kanba S (2014) A case of late-onset bipolar disorder with severely abnormal behavior and neuroimaging observations very similar to those of frontotemporal dementia. J Neuropsychiatr Clin Neurosci 26(1):E35-E35

Murguia JR, Belles JM, Serrano R (1995) A salt-sensitive $3^{\prime}\left(2^{\prime}\right), 5^{\prime}$ bisphosphate nucleotidase involved in sulfate activation. Science (New York, N.Y.) 267(5195):232-234

Naylor CE, Bagnéris C, DeCaen PG, Sula A, Scaglione A, Clapham DE, Wallace BA (2016) Molecular basis of ion permeability in a voltage-gated sodium channel. EMBO J 35(8):820-830

Nelson J Craig, Baumann P, Delucchi K, Joffe R, Katona C (2014) A systematic review and meta-analysis of lithium augmentation of tricyclic and second generation antidepressants in major depression. J Affect Disord 168:269-275

Novetsky AP, Thompson DM, Zighelboim I, Thaker PH, Powell MA, Mutch DG, Goodfellow PJ (2013) Lithium and inhibition of GSK3 $\beta$ as a potential therapy for serous ovarian cancer. Int $\mathbf{J}$ Gynecol Cancer 23(2):361

Nunes PV, Forlenza OV, Gattaz WF (2007) Lithium and risk for Alzheimer's disease in elderly patients with bipolar disorder. Brit J Psychiatr 190(4):359-360

O'Brien W, Harper AD, Jové F, Woodgett JR, Maretto S, Piccolo S, Klein PS (2004) Glycogen synthase kinase-3 $\beta$ haploinsufficiency mimics the behavioral and molecular effects of lithium. J Neurosci 24(30):6791-6798

Ohgami H, Terao T, Shiotsuki I, Ishii N, Iwata N (2009) Lithium levels in drinking water and risk of suicide. Brit J Psychiatr 194(5):464-465 
Orlowski J, Grinstein S (2004) Diversity of the mammalian sodium/ proton exchanger SLC9 gene family. Pflügers Archiv 447(5):549-565

Petrezselyova S, Zahradka J, Sychrova H (2010) Saccharomyces Cerevisiae BY4741 and W303-1A laboratory strains differ in salt tolerance. Fungal Biol 114(2-3):144-150

Pickett EE, O'Dell BL (1992) Evidence for dietary essentiality of lithium in the rat. Biol Trace Elem Res 34(3):299-319

Piovesan D, Profiti G, Martelli PL, Casadio R (2012) "The human" magnesome": detecting magnesium binding sites on human proteins. BMC Bioinform 13(14): 1

Porteous DJ, Kirsty Millar J, Brandon NJ, Sawa A (2011) DISC1 at 10: connecting psychiatric genetics and neuroscience. Trends Mol Med 17(12):699-706

Post RM (2007) Role of BDNF in bipolar and unipolar disorder: clinical and theoretical implications. J Psychiatr Res 41(12):979-990

Pottegård A, Hallas J, Jensen BL, Madsen K, Friis S (2015) Longterm lithium use and risk of renal and upper urinary tract cancers. J Am Soc Nephrol: ASN-2015010061

Pottegård A, Ennis ZN, Hallas J, Jensen BL, Madsen K, Friis S (2016) Long-term use of lithium and risk of colorectal adenocarcinoma: a nationwide case-control study. Br J Cancer 114(5):571-575

Price LH, Charney DS, Delgado PL, Heninger GR (1990) Lithium and serotonin function: implications for the serotonin hypothesis of depression. Psychopharmacology 100(1):3-12

Prior C, Potier S, Souciet J-L, Sychrova H (1996) Characterization of the NHA1 gene encoding a $\mathrm{Na}+/ \mathrm{H}+$-antiporter of the yeast Saccharomyces cerevisiae. FEBS Lett 387(1):89-93

Rahav-Manor O, Carmel O, Karpel R, Taglicht D, Glaser G, Schuldiner S, Padan E (1992) NhaR, a protein homologous to a family of bacterial regulatory proteins (LysR), regulates nhaA, the sodium proton antiporter gene in Escherichia coli. J Biol Chem 267(15):10433-10438

Rasola A, Chiara F (2013) GSK-3 and mitochondria in cancer cells. Front Oncol 3:16

Refaeli B, Giladi M, Hiller R, Khananshvili D (2016) Structure-based engineering of lithium-transport capacity in an archaeal sodiumcalcium exchanger. Biochemistry 55(12):1673-1676

Rezin GT, Amboni G, Zugno AI, Quevedo J, Streck EL (2009) Mitochondrial dysfunction and psychiatric disorders. Neurochem Res 34(6): 1021

Richelson E (1977) Lithium ion entry through the sodium channel of cultured mouse neuroblastoma cells: a biochemical study. Science 196(4293):1001-1002

Rookmaaker MB, van Gerven HA, Goldschmeding R, Boer WH (2012) Solid renal tumours of collecting duct origin in patients on chronic lithium therapy. Clin Kidney J 5(5):412-415

Roux M, Bloom M (1990) $\mathrm{Ca} 2+, \mathrm{Mg} 2+, \mathrm{Li}+, \mathrm{Na}+$, and $\mathrm{K}+$ distributions in the headgroup region of binary membranes of phosphatidylcholine and phosphatidylserine as seen by deuterium NMR. Biochemistry 29(30):7077-7089

Rubin-Bejerano I, Sagee S, Friedman O, Pnueli L, Kassir Y (2004) The in vivo activity of Ime1, the key transcriptional activator of meiosis-specific genes in Saccharomyces cerevisiae, is inhibited by the cyclic AMP/protein kinase A signal pathway through the glycogen synthase kinase $3-\beta$ homolog Rim11. Mol Cell Biol 24(16):6967-6979

Ruiz A, Arino J (2007) Function and regulation of the saccharomyces cerevisiae ENA sodium ATPase system. Eukaryot Cell 6(12):1. https://doi.org/10.1128/EC.00337-07

Ryves WJ, Harwood AJ (2001) Lithium inhibits glycogen synthase kinase- 3 by competition for magnesium. Biochem Biophys Res Commun 280(3):720-725

Sapolsky RM, Michael Romero L, Munck AU (2000) How do glucocorticoids influence stress responses? Integrating permissive, suppressive, stimulatory, and preparative actions 1 . Endocr Rev 21(1):55-89

Schou M (1968) Lithium in psychiatric therapy and prophylaxis. J Psychiatr Res 6(1):67-95

Schrauzer GN (2002) Lithium: occurrence, dietary intakes, nutritional essentiality. J Am Coll Nutr 21(1):14-21

Schrauzer GN, Shrestha KP (1990) Lithium in drinking water and the incidences of crimes, suicides, and arrests related to drug addictions. Biol Trace Elem Res 25(2):105-113

Schwochau K (1984) Extraction of metals from sea water. In: Inorganic chemistry. Springer Berlin Heidelberg, pp 91-133

Shalbuyeva N, Brustovetsky T, Brustovetsky N (2007) Lithium desensitizes brain mitochondria to calcium, antagonizes permeability transition, and diminishes cytochrome $\mathrm{C}$ release. J Biol Chem 282(25):18057-18068

Sheard MH (1971) Effect of lithium on human aggression. Nature

Silva R, Mesquita AR, Bessa J, Sousa JC, Sotiropoulos I, Leao P, Almeida OFX, Sousa N (2008) Lithium blocks stress-induced changes in depressive-like behavior and hippocampal cell fate: the role of glycogen-synthase-kinase-3 $\beta$. Neuroscience 152(3):656-669

Singh KK, Ge X, Mao Y, Drane L, Meletis K, Samuels BA, Tsai L-H (2010) Dixdc1 is a critical regulator of DISC1 and embryonic cortical development. Neuron 67(1):33-48

Singh N, Halliday AC, Thomas JM, Kuznetsova O, Baldwin R, Woon EC, Aley PK et al (2013) A safe lithium mimetic for bipolar disorder. Nat Commun 4:1332

Snyder JS, Soumier A, Brewer M, Pickel J, Cameron HA (2011) Adult hippocampal neurogenesis buffers stress responses and depressive behaviour. Nature 476(7361):458-461

Song J, Franck J, Pincus P, Won Kim M, Han S (2014) Specific ions modulate diffusion dynamics of hydration water on lipid membrane surfaces. J Am Chem Soc 136(6):2642-2649

Souza FG, Goodwin GM (1991) Lithium treatment and prophylaxis in unipolar depression: a meta-analysis. Brit J Psychiatr 158(5):666-675

Spiegelberg BD et al (2005) Alteration of lithium pharmacology through manipulation of phosphoadenosine phosphate metabolism. J Biol Chem 280(7):5400-5405. doi:10.1074/ jbc.M407890200

Spiegelberg BD, Dela Cruz J, Law T-H, York JD (2005) Alteration of lithium pharmacology through manipulation of phosphoadenosine phosphate metabolism. J Biol Chem 280(7):5400-5405

Stambolic V, Ruel L, Woodgett JR (1996) Lithium inhibits glycogen synthase kinase-3 activity and mimics wingless signalling in intact cells. Curr Biol 6(12):1664-1669

Suizu T, Tsutsumi H, Kawado A, Murata K, Imayasu S (1994) On the importance of calcium and magnesium ions in yeast sporulation. J Ferment Bioeng 77(3):274-276

Sun A, Shanmugam I, Song J, Terranova PF, Brantley Thrasher J, Li B (2007) Lithium suppresses cell proliferation by interrupting E2F-DNA interaction and subsequently reducing S-phase gene expression in prostate cancer. Prostate 67(9):976-988

Szabo I, Zoratti M (2014) Mitochondrial channels: ion fluxes and more. Physiol Rev 94(2):519-608

Szentistvanyi I, Janka Z, Joo F, Rimanoczy A, Juhasz A, Latzkovits L (1979) Na-dependent Li-transport in primary nerve cell cultures. Neurosci Lett 13(2):157-161

Szklarczyk D, Morris JH, Cook H, Kuhn M, Wyder S, Simonovic M, Santos A et al (2016) The STRING database in 2017: qualitycontrolled protein-protein association networks, made broadly accessible. Nucleic Acids Res gkw937

Tasneem A, Iyer LM, Jakobsson E, Aravind L (2004) Identification of the prokaryotic ligand-gated ion channels and their implications 
for the mechanisms and origins of animal Cys-loop ion channels. Genome Biol 6(1):R4

Thompson AN, Kim I, Panosian TD, Iverson TM, Allen TW, Nimigean CM (2009) Mechanism of potassium-channel selectivity revealed by $\mathrm{Na}+$ and $\mathrm{Li}+$ binding sites within the KcsA pore. Nat Struct Mol Biol 16(12):1317-1324

Thomsen K, Shirley DG (2006) A hypothesis linking sodium and lithium reabsorption in the distal nephron. Nephrol Dial Transpl 21(4):869-880

Treiser SL, Cascio CS, O’Donohue TL, Thoa NB, Jacobowitz DM, Kellar KJ (1981) Lithium increases serotonin release and decreases serotonin receptors in the hippocampus. Science 213(4515):1529-1531

Tsuruta T (2005) Removal and recovery of lithium using various microorganisms. J Biosci Bioeng 100(5):562-566

Turekian KK, Wedepohl KH (1961) Distribution of the elements in some major units of the earth's crust. Geol Soc Am Bull 72(2):175-192

Ushikubo T, Kita NT, Cavosie AJ, Wilde SA, Rudnick RL, Valley JW (2008) Lithium in Jack Hills zircons: evidence for extensive weathering of Earth's earliest crust. Earth Planet Sci Lett 272(3):666-676

Uwai Y, Arima R, Takatsu C, Furuta R, Kawasaki T, Nabekura T (2014) Sodium-phosphate cotransporter mediates reabsorption of lithium in rat kidney. Pharmacol Res 87:94-98

Valvassori SS, Rezin GT, Ferreira CL, Moretti M, Gonçalves CL, Cardoso MR, Streck EL, Kapczinski F, Quevedo J (2010) Effects of mood stabilizers on mitochondrial respiratory chain activity in brain of rats treated with d-amphetamine. J Psychiatr Res 44(14):903-909

Van Dijken P et al (1996) Dictyostelium discoideum contains three inositol monophosphatase activities with different substrate specificities and sensitivities to lithium. Biochem J 314(Pt 2):491-495

van Werven FJ, Amon A (2011) Regulation of entry into gametogenesis. Philos Trans R Soc Lond Ser B 366(1584):3521-3531, doi:10.1098/rstb.2011.0081

Varma S, Rempe SB (2008) Structural transitions in ion coordination driven by changes in competition for ligand binding. $\mathrm{J}$ Am Chem Soc 130(46): 15405-15419

Vereninov IA, Yurinskaya VE, Model MA, Vereninov AA (2016) Unidirectional flux balance of monovalent ions in cells with $\mathrm{Na} /$ $\mathrm{Na}$ and $\mathrm{Li} / \mathrm{Na}$ exchange: experimental and computational studies on lymphoid U937 cells. PLoS ONE 11(5):e0153284

Vlachy N, Jagoda-Cwiklik B, Vácha R, Touraud D, Jungwirth P, Kunz W (2009) Hofmeister series and specific interactions of charged headgroups with aqueous ions. Adv Coll Interface Sci 146(1):42-47

Wang H-Y, Friedman E (1999) Effects of lithium on receptormediated activation of $\mathrm{G}$ proteins in rat brain cortical membranes. Neuropharmacology 38(3):403-414
Weinstein G, Beiser AS, Choi SH, Preis SR, Chen TC, Vorgas D, Rhoda A et al (2014) Serum brain-derived neurotrophic factor and the risk for dementia: the Framingham Heart Study. JAMA Neurol 71(1):55-61

Wieland J, Nitsche AM, Strayle J, Steiner H, Rudolph HK (1995) The PMR2 gene cluster encodes functionally distinct isoforms of a putative $\mathrm{Na}+$ pump in the yeast plasma membrane. EMBO J 14(16):3870

Woolley JD, Khan BK, Murthy NK, Miller BL, Rankin KP (2011) The diagnostic challenge of psychiatric symptoms in neurodegenerative disease: rates of and risk factors for prior psychiatric diagnosis in patients with early neurodegenerative disease. J Clin Psychiatr 72(2):1-478

Yatham LN, Kennedy SH, Parikh SV, Schaffer A, Beaulieu S, Alda M, O'Donovan C et al (2013a) Canadian Network for Mood and Anxiety Treatments (CANMAT) and International Society for Bipolar Disorders (ISBD) collaborative update of CANMAT guidelines for the management of patients with bipolar disorder: update 2013. Bipolar Disord 15(1):1-44

Yatham LN, Kennedy SH, Parikh SV, Schaffer A, Beaulieu S, Alda M, O'Donovan C et al (2013) Canadian Network for Mood and Anxiety Treatments (CANMAT) and International Society for Bipolar Disorders (ISBD) collaborative update of CANMAT guidelines for the management of patients with bipolar disorder: update 2013. Bipolar Disord 15(1):1-44

York JD, Ponder JW, Majerus PW (1995) Definition of a metaldependent/Li(+)-inhibited phosphomonoesterase protein family based upon a conserved three-dimensional core structure. In: Proc Natl Acad Sci USA 92(11):5149-5153

Yoshikawa T, Honma S (2016) Lithium lengthens circadian period of cultured brain slices in area specific manner. Behav Brain Res 314:30-37

Yurinskaya VE, Moshkov AV, Goryachaya TS, Vereninov AA (2014) $\mathrm{Li} / \mathrm{Na}$ exchange and $\mathrm{Li}$ active transport in human lymphoid cells U937 cultured in lithium media. Cell Tissue Biol 8(1):80-90

Zaidan M, Stucker F, Stengel B, Vasiliu V, Hummel A, Landais P, Boffa J-J, Ronco P, Grünfeld J-P, Servais A (2014) Increased risk of solid renal tumors in lithium-treated patients. Kidney Int 86(1):184-190

Zarse K, Terao T, Tian J, Iwata N, Ishii N, Ristow M (2011) Lowdose lithium uptake promotes longevity in humans and metazoans. Eur J Nutr 50(5):387-389

Zhu Q, Yang J, Han S, Liu J, Holzbeierlein J, Brantley Thrasher J, Li B (2011) Suppression of glycogen synthase kinase 3 activity reduces tumor growth of prostate cancer in vivo. Prostate $71(8): 835-845$

Zörgö E, Chwialkowska K, Gjuvsland AB, Garré E, Sunnerhagen P, Liti G, Blomberg A, Omholt SW, Warringer J (2013) Ancient evolutionary trade-offs between yeast ploidy states. PLoS Genet 9(3):e1003388 